\title{
A FENOMENOLOGIA DO ESPÍRITO DE HEGEL E
}

\section{A UNIDADE DE SUA FILOSOFIA:}

\section{UMA REAVALIAÇÃO SISTEMÁTICA}

(Hegel's Phenomonology of Spirit, and the unity of his philosophy: A systematic reappraisal)

\section{Lorenz B. Puntel - Universidade de Munique*}

Resumo: 0 estudo partirá da seguinte pergunta: como explicar o fato surpreendente que desde a década de 1930 até hoje o livro de Hegel, escrito em 1807, tenha influenciado e, na verdade, fascinado um número significativo de filósofos? Uma tentativa de resposta a esta questão será dada no final do trabalho. Importante para a compreensão deste estudo é o fato que, na filosofia recente e contemporânea, o termo "sistemático" possui dois sentidos diferentes: o primeiro é o de não-histórico (= sistemático $)_{1}$, o segundo 0 de "holístico, abrangente" (= sistemático $)_{2}$. A expressão "perspectiva sistemática", no título do trabalho, deve ser entendida em ambos os sentidos, mas os dois sentidos são combinados de uma forma na Parte 1 do artigo e de outra na Parte 2. A Parte 1 contém uma reavaliação não-sistemática, e sistemática, da Fenomenologia no sentido de uma reinterpretação de sua arquitetônica interna e de seu lugar sistemático ${ }_{2}$ no interior do sistema filosófico hegeliano da maturidade. A Parte 2 apresenta algumas considerações, tanto negativas como positivas, a partir de uma perspectiva sistemática ${ }_{1+2}$. Negativamente, a Parte 2 mostra que, dado o objetivo do livro, seu status fenomenológico é altamente problemá-

\footnotetext{
* Artigo submetido à avaliação no dia 15/12/2008 e aprovado para publicação no dia 21/02/2009. Tradução do original inglês inédito. Para as citações da Fenomenologia do Espírito e da Enciclopédia das Ciências Filosóficas (1830) foram utilizadas, com pequenas alteraç̃̃es, as traduções de Paulo MENESES: G.W.F. Hegel: Fenomenologia do Espírito. Vol. I-II. Petrópolis: Vozes, 1992; G.W.F. Hegel: Enciclopédia das Ciências Filosóficas em Compêndio (1830). Vol. I-III, São Paulo: Loyola, 1995-1997.
} 
tico sob vários aspectos, especialmente no que concerne à concepção do saber absoluto, com a qual o livro culmina, e à dimensão lógica, para a qual ele pretende preparar o caminho. A Parte 2 demonstra também, ao contrário de posições mantidas por muitos intérpretes contemporâneos, que a obra carece de coerência interna em relação tanto ao método como ao conteúdo. Positivamente, o estudo tenta mostrar que uma certa idéia fenomenológica, em um sentido algo semelhante ao de Hegel, poderia ser aceita e elaborada no contexto da filosofia sistemático-estrutural que o autor apresenta em seu livro Estrutura e ser. Um quadro referencial teórico para uma filosofia sistemática (São Leopoldo: Editora Unisinos, 2008).**

Palavras-chave: Hegel, Fenomenologia do Espírito, Perspectiva sistemática, Filosofia estrutural-sistemática.

Abstract. The essay will start by asking the question how to explain the surprising fact that from the 1930s up to the present, Hegel=s book, written in 1807, has deeply influenced and indeed has fascinated a significant number of philosophers. A tentative answer to this question will be given at the end of the lecture. Important to the essay is the fact that, within recent and contemporary philosophy, the term 'systematic' has two different senses: the first is that of "nonhistorical" (= systematic $)$, the second, that of "holistic, comprehensive" (= systematic $c_{2}$. The expression 'systematic perspective,' in the title of the lecture, is to be understood in both senses, but the two senses are combined in one way in Part 1 of the lecture, and in another way in Part 2. Part 1 contains a non-systematic $c_{1}$ and systematic, reappraisal of the Phenomenology in the sense of a reinterpretation of its inner architectonic and of its systematc, place within Hegel $=s$ mature system of philosophy. Part 2 presents some critical negative as well as positive considerations from a systematic $c_{1+2}$ perspective. Negatively, Part 2 shows that given the aim[s] of the book, its phenomenological status is highly problematic in various respects, particularly concerning the conception of absolute knowing with which the book culminates and the logical dimension for which it is supposed to prepare the way. Part 2 also demonstrates, in opposition to positions held by many contemporary interpreters, that the work lacks inner coherence with respect both to method and to content. Positively, the essay attempts to show that a certain phenomenological idea in a sense somewhat similar to Hegel's could be accepted and elaborated within the structural-systematic philosophy the author presents in his book Estrutura e ser. Um quadro referencial teórico para uma filosofia sistemática. S. Leopoldo, Brasil: Editora Unisinos, 2008).

Key-words: Hegel, the Phenomenology of Spirit, Systematic Perspective, structural-systematic Philosophy.

** A edição original alemã apareceu em 2006; uma tradução inglesa foi publicada em 2008 


\section{Introdução}

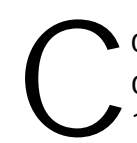

omo explicar o fato surpreendente que desde a década de 1930 até o presente o livro de Hegel Fenomenologia do Espírito, publicado em 1807, tenha influenciado profundamente e, na verdade, fascinado um número significativo de filósofos? Uma tentativa de resposta a esta questão pode ser dada apenas no final deste artigo.

Na realidade a Fenomenologia do Espírito de Hegel não teve uma profunda influência em todas as épocas desde sua publicação em 1807. Setenta e três anos depois, em 1880, o filósofo alemão Wilhelm Wimdelband escreveu:

[...] a geração que é capaz de entender a riqueza dessa obra está desaparecendo. $E$ deve-se temer que em um futuro não muito distante ninguém será capaz de fazêlo. Mesmo agora, aqueles que leram o livro do princípio ao fim poderiam ser contados nos dedos da mão. ${ }^{1}$

A principal razão da avaliação de Windelband a respeito da primeira grande obra de Hegel pode ser vista no quase exclusivo interesse no sistema de filosofia da maturidade de Hegel que dominou a interpretação e a crítica da filosofia hegeliana durante quase todo o primeiro século depois de sua morte em 1831. Este fato é de importância decisiva porque, como se mostra mais à frente neste artigo, a concepção apresentada na Fenomenologia do Espírito como tal não é uma parte integrante do sistema. Daí se segue que o sistema e a Fenomenologia diferem de modo muito significativo.

A situação começou a mudar lentamente somente no começo do século 20, quando Hermann Nohl publicou a primeira edição de Hegels Theologische Jugendschriften (1907)² e Georg Lasson iniciou a nova edição das obras de Hegel (1911). A despeito desses acontecimentos, contudo, uma investigação intensa, mas parcial, sobre a obra juvenil de Hegel não começou na França e na Alemanha até duas décadas mais tarde, na década de 30 do século passado. Na França, o filósofo A lexandre Kojève, nascido na Rússia, ministrou um famoso curso sobre a Fenomenologia de Hegel na École Pratique des Hautes Études de 1933 a 1939. Sua leitura da obra baseava-se na dialética do senhor-escravo eno conceito de reconhecimento (A nerkennung). Ele influenciou profundamente os filósofos franceses incluindo nomes como Jean-Paul Sartre, Jacques Derrida e Michel Foucault. N esta mesma tradição,

\footnotetext{
${ }^{1}$ WINDELBAND, W. Geschichte der neueren Philosophie Vol. 2, Leipzig: Breitkopf \& Härtel. 1880, p. 311. Nas edições 7ạ e 8a do volume, publicadas em 1922, Windelband qualifica de algum modo esta predição pessimista omitindo a frase: "E deve-se temer que em um futuro não muito distante ninguém será capaz de fazêlo." Doze anos depois da morte de Hegel, A. Trendelenburg escrevia: "Não se deveria falar demais da Fenomenologia. Ela é e permanece um liber laudatus magis quam lectus."

2 Tradução inglesa: Hegel's Early Theological Manuscripts, trans. T. M. Knox. Chicago: Chicago University Press, 1948.
} 
Jean Hyppolite realizou a primeira tradução francesa da Fenomenologia de Hegel em 1939 e publicou um extenso comentário desta obra em $1946,{ }^{3}$ que teve uma grande influência. Na esteira de Kojèvee Hyppolitea Fenomenologia de Hegel tornou-se uma das obras filosóficas mais intensamente estudadas e interpretadas na França. Uma obra característica que data desse período é Structures et mouvement dialectique dans la Phénoménologie de l'Esprit de Hegel de P.-J. Labarrière. ${ }^{4}$ Influenciado pelo lingüista F. de Saussure e pelo Estruturalismo francês Labarrière tenta apresentar o que se poderia chamar de uma "leitura pura" da Fenomenologia. O objetivo de seu livro é, em suas próprias palavras, o seguinte:

entender a Fenomenologia, compreender esta obra ut jacet, mediante a investigação de suas estruturas e do movimento que as anima [...]. O postulado subjacente é o seguinte: para ser entendida, a obra não requer qualquer conhecimento prévio; a obra em si mesma, em função da necessidade que a anima, detém a chave para sua própria decifração. Para encontrar o caminho de acesso à obra, basta ser aquela consciência ingênua que Hegel expõe inicialmente na sua mais rica e mais empobrecida certeza. ${ }^{5}$

$\mathrm{Na}$ A lemanha, o estudo da Fenomenologia concentrou-se inicial mente nos aspectos históricos da obra, e, mais tarde, nos problemas da reedição crítica das obras de Hegel e em questões referentes ao lugar da obra no sistema hegeliano. Uma fase completamente nova do estudo de Hegel foi iniciada pelos filósofos analíticos que começaram a estudar e comentar a Fenomenologia. A maioria deles concentrou-se exclusivamente em al gumas partes da obra ou em algumas "intuições" (insights) que eles acreditaram ter encontrado nela. Um típico exemplo desta abordagem éa tese de Robert Brandom, segundo a qual há "temas pragmatistas no idealismo de Hegel", o que ele procura mostrar interpretando a seu modo al gumas passagens dos capítulos iniciais da Fenomenologia. ${ }^{6}$ Esses filósofos analíticos não estão absolutamente interessados em esclarecer o status específico da Fenomenologia como um todo no conjunto da filosofia hegeliana.

Este artigo pretende reavaliar a Fenomenologia a partir de uma perspectiva inteiramente diferente, i.e. a partir de uma perspectiva sistemática. Isso requer, em primeiro lugar, que o significado exato de "sistemático" seja explicado. Importante para esse estudo é o fato que, na filosofia recente e contemporânea, o termo "sistemático" tem dois sentidos diferentes: o primeiro é o de "não-histórico" (= "sistemático"), o segundo, o de "holístico,

\footnotetext{
${ }^{3}$ Genèse et Structure de la Phénoménologie de l'Esprit, 2 vol. Paris, Gallimard, 1946.

4 Paris: Aubier-Montaigne, 1968.

${ }^{5}$ Ib. p. 29.

6 Veja-se BRANDOM, S. "Some Pragmatist Themes in Hegel 's I dealism", in: European J ournal of Philosophy, Agosto 1999, p. 164-189; reeditado em: BRANDON, R. Tales of the Mighty Dead. Historical Essays in the Metaphysics of Intentionality. Cambridge, Ma and London: Harvard University Press, 2002, p. 210-234.
} 
abrangente" (= "sistemático"). A expressão "sistemático", no título do artigo, deve ser entendida em ambos os sentidos. Mas os dois sentidos estão combinados de uma forma na Parte 1 do artigo e de outra forma na Parte 2. A orientação da primeira parte do trabalho é fundamentalmente nãosistemática ${ }_{1}$, mas sistemática ${ }_{2}$ O caráter sistemático ${ }_{2}$ das considerações tem dois aspectos: primeiro, a Parte 1 considera o status não-sistemático ${ }_{1}(=$ interpretativo) e sistemático ${ }_{2}$ da obra considerada como tal, independentemente da questão de seu lugar no sistema de filosofia; segundo, o lugar nãosistemático ( interpretativo) e sistemático ${ }_{2}$ da Fenomenologia no projeto hegeliano de desenvolver um sistema filosófico oniabrangente. A Parte 2

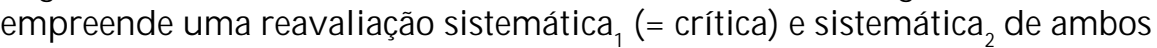
os aspectos.

\section{Uma reavaliação interpretativa da Fenomenologia primeiro em si mesma e depois no conjunto do Sistema de Filosofia de Hegel}

\subsection{A Fenomenologia em si mesma, como um todo}

\subsubsection{O objetivo explícito original da Fenomenologia, ou seja,} sua intenção e método

Esta seção pressupõe o conhecimento da complexa história da composição da Fenomenologia e introduz apenas al gumas questões importantes relativas a essa história.

Hegel descreve o objetivo ou intenção da Fenomenologia, ao longo de todas as fases de seu desenvolvimento, como sendo a introdução ou o caminho ou a elevação da consciência natural ou ingênua, ou a sua preparação, para a ciência ou saber absoluto ou pensar. Isso deixa claro que a tarefa central de sua reavaliação interpretativa deve ser explicar o que exatamente se entende por "ciência" ou "saber absoluto" ou "pensar". O que muda ao longo do desenvolvimento do pensamento de Hegel, como se mostrará logo mais, é o lugar metódico e sistemático que Hegel atribui à Fenomenologia

Esta introdução/ caminho/ elevação/ preparação, enquanto objetivo da Fenomenologia, consiste na articulação completa da experiência:

A experiência que a consciência faz sobre si mesma não pode abranger nela, segundo seu conceito, nada menos que o sistema completo da consciência ou o reino total da verdade do espírito. Seus momentos se apresentam assim nessa determinidade peculiar, de não serem momentos abstratos ou puros, mas sim, tais como são para a consciência ou como a mesma aparece 
em sua relação para com eles; por isso os momentos do todo são figuras da consciência. (Fenom. I 72-73) ${ }^{7}$

A consciência, cuja total auto-experiência Hegel pretende articular, apresenta-se no seu ponto de partida como contendo uma profunda oposição ou não-correspondência entre dois fatores que Hegel caracteriza de diferentes modos. Um dos fatores é chamado "saber" ou "o conceito" ou o objeto "para nós ou para a consciência”, o outro é chamado "(a) verdade (do objeto)" ou "o objeto em si mesmo" ou "o ser". A tarefa é expor o processo de superar a oposição ou não-correspondência. Como isso se realiza é descrito por Hegel em algumas formulações famosas, p. ex.:

A consciência fornece, em si mesma, sua própria medida; motivo pelo qual a investigação se torna uma comparação de si consigo mesma, já que a distinção que acaba de ser feita incide na consciência. (Fenom. I 79) ${ }^{8}$

A terminologia de Hegel é altamente problemática, na verdade, quase ininteligível, como deixa claro a passagem seguinte:

Este movimento dialético que a consciência exercita em si mesma, tanto em seu saber como em seu objeto, enquanto dele surge o novo objeto verdadeiro para a consciência, é justamente o que se chama experiência. (Fenom. ( 71$)^{9}$

Certamente "objeto" não pode ser entendido aqui no sentido usual etampouco no sentido que tem este termo, p. ex., na Crítica da Razão Pura de Kant. Em vez disso, será mais bem entendido como designando um dos pólos da relação de oposição que Hegel introduz no início (veja-se acima). Mas o significado positivo de "objeto" na Fenomenologia requer uma explicação cuidadosa e detal hada. Isso será feito criticamente na Parte 2 deste estudo (veja-se Seção 2.1.3 [2]).

\footnotetext{
7 Die Erfahrung, welche das Bewusstsein über sich macht, kann ihrem Begriffe nach nichts weniger in sich begreifen als das ganze System desselben, oder das ganze Reich der Wahrheit des Geistes, so dass die Momente derselben in dieser eigentümlichen Bestimmtheit sich darstellen, nicht abstrakte, reine Momente zu sein, sondern so, wie sie für das Bewusstsein sind, oder wie dieses selbst in seiner Beziehung auf sie auftritt, wodurch die Momente des Ganzen Gestalten des Bewusstseins sind. (PhG 68 [61])

${ }^{8}$ Das Bewusstsein gibt seinen Maßstab an ihm selbst, und die Untersuchung wird dadurch eine Vergleichung seiner mit sich selbst sein; denn die Unterscheidung, welche soeben gemacht worden ist, fällt in es. (PhG 64[59])

${ }^{9}$ Diese dialektische Bewegung, welche das Bewusstsein an ihm selbst, sowohl an seinem Wissen als auch an seinem Gegenstand ausübt, in sofern ihm der neue wahre Gegenstand daraus entspringt, ist eigentlich dasjenige, was Erfahrung genannt wird. (PhG 66 [60])
} 


\subsubsection{A estrutura elementar e a estrutura plena ou concreta da Fenomenologia}

No caminho apresentado na Fenomenologia, a consciência atravessa uma série de formas ou configurações ou paradigmas (Gestaltungen), e esta travessia proporciona "a história detal hada da formação para a ciência da própria consciência" (Fenom. I,67). ${ }^{10}$ Tomando a Fenomenologia ut jacet, esta história detalhada começa com a consciência natural e ingênua no nível-zero de certeza, i.e. no nível da experiência sensível, e termina com a mais alta Gestalt ou configuração concreta, que Hegel chama de "saber absoluto". É uma longa história. Como é bem conhecido, a Fenomenologia de Hegel é uma obra extensa, que contém um rico material em quase todas as áreas, o qual de um ou outro modo tem fornecido tópicos de reflexão, não só para filósofos, mas também para historiadores, juristas, teólogos, etc. O livro é dividido em oito capítulos (I-VIII), mas esta divisão é substituída por uma divisão em três partes, que só aparece no Índice: (A) Consciência (Capítulos I-III), (B) Auto-consciência (Capítulo IV), (C) (AA) Razão (Capítulo V), (BB) Espírito (Capítulo VI), (CC) Religião (Capítulo VII) e(DD) Saber absoluto (Capítulo VIII). A divisão em partes e sub-partes expressa a estrutura fenomenológica global do livro, ao passo que a divisão em capítulos indica individualmente as princi pais estações do percurso fenomenológico (ou configurações da consciência).

A maioria dos intérpretes da Fenomenologia sempre admitiu que a transição do capítulo V ao capítulo VI (ou da sub-parte (C) (AA) à sub-parte (C) (BB), i.e. da Razão ao Espírito, implica uma espécie de ruptura na obra. Muitos intérpretes concluíram que a ruptura resulta do fato de ter Hegel alterado profundamente a abordagem ou a idéia guia do livro ao compô-lo. Esses intérpretes consideram que a Fenomenologia consiste de duas partes drasticamente diferentes. Em seu livro Darstellung, Methode und Struktur. Untersuchung zur Einheit der systematischen Philosophie G. W. F. Hegels, ${ }^{11}$ este autor mostrou que Hegel real mente mudou o objetivo do livro, mas não modificou sua idéia fundamental. Mudou apenas a abrangência da idéia. Originalmente, o propósito de Hegel era não apresentar a dimensão fenomenológica em toda a sua extensão; sua intenção era apresentar apenas Darstellung, Methode, Struktur daquilo que ele chama na mesma obra de estrutura elementar da dimensão fenomenológica. No decurso da redação Hegel decidiu apresentar a dimensão fenomenológica em sua plena abrangência, i.e. não só na sua estrutura elementar mas também na sua estrutura completa. Esta interpretação explica cabal mente o fato que Hegel propõe dois subtítulos muito diferentes da obra: Ciência da experiência da

\footnotetext{
${ }^{10}$ die ausführliche Geschichte der Bildung des Bewusstseins selbst zur Wissenschaft (PhG 61 [56]).

${ }^{11}$ Bonn: Bouvier Verlag Herbert Grundmann, ${ }^{2} 1981$.
} 
consciência (este era o subtítulo primeiro e original) e Ciência da Fenomenologia do Espírito. ${ }^{12}$ Isso deve ser agora brevemente explicado.

A estrutura elementar da dimensão fenomenológica é a da experiência da consciência através das seguintes etapas: consciência imediata / auto-consciência / razão. Razão é o nível no qual a perfeita correspondência entre saber e verdade aparece pela primeira vez, ou seja, no nível elementar: este é o nível que Hegel mais tarde, na Enciclopédia, chama de "a dimensão formal (ou a mera forma) da pura consciência" (das Formelle des blossen Bewusstseins). ${ }^{13} \mathrm{~A}$ esta altura, o objetivo da Fenomenologia já é atingido. A esta altura, Hegel poderia ter passado imediatamente para a dimensão da Ciência no seu sentido, i.e. do saber absoluto. Mas ele não o fez. Por quenão, e exatamente em que sentido? Duas razões podem ser aduzidas: uma global e uma espeć́fica.

A razão global éque na época da composição da Fenomenologia, ainda não estava inteiramente claro para Hegel o significado da dimensão que ele chamou (dimensão da) ciência (do saber/ pensar absoluto ou puro, do espírito absoluto). Retornaremos a este ponto na Parte 2.

A razão específicaéindicada pelo próprio Hegel em termos de rara clareza, especial mente no $\S 25$ da Enciclopédia, onde el e escreve o seguinte:

Na minha Fenomenologia do Espírito, que, por isso, quando se publicou foi designada como a primeira parte do Sistema da Ciência, tomou-se o caminho de começar pela primeira [e] mais simples manifestação do espírito, pela consciência imediata, e de desenvolver sua dialética até ao ponto de vista da ciência filosófica, cuja necessidade é mostrada através dessa progressão. Mas para isso não se podia ter ficado no formal da simples consciência; pois o ponto de vista do saber filosófico é em si ao mesmo tempo o mais rico de conteúdo e o mais concreto; por conseguinte, ao emergir como resultado, ele pressupunha também as figuras concretas da consciência, como, por exemplo, as figuras da moral, da ética, da arte, da religião. O desenvolvimento do conteúdo, dos objetos [que são] partes características da ciência filosófica, incide pois ao mesmo tempo nesse desenvolvimento da consciência - que inicialmente parecia restrito apenas ao formal. Esse desenvolvimento deve, por assim dizer, avançar por detrás da consciência, na medida em que o conteúdo se relaciona com a consciência como o Em-si. A exposição torna-se, por isso, mais complicada e no que se refere às partes concretas, já recai parcialmente naquela introdução. (Encicl. § 25, nota) ${ }^{14}$

\footnotetext{
${ }^{12}$ Em algumas cópias a obra tem os dois subtítulos, noutras apenas um deles. Vejase Gesammelte Werke, Bd. 9, p. 469ss.

${ }^{13}$ Enciclopédia, § 25 nota.

14 In meiner Phänomenologie des Geistes, welche deswegen bei ihrer Herausgabe als der erste Theil des Systems der Wissenschaft bezeichnet worden, ist der Gang genommen, von der ersten einfachsten Erscheinung des Geistes, dem unmittelbaren
} 
Porque ele tinha decidido integrar "as formações concretas da consciência (die konkreten Gestalten des Bewusstseins)" na dimensão da experiência da consciência, Hegel caracterizou a razão apenas como

a certeza de ser toda a realidade. Mas esse Em-si ou esta realidade é, ainda, um absolutamente universal: é a pura abstração da realidade. (Fenom. I $155)^{15}$

Em outras palavras, há ainda uma quantidade enorme de material que deve ser articulada, a fim de alcançar a correspondência plenamente concreta de saber e verdade, de saber e realidade.

É preciso sublinhar que a estrutura plenamente concreta não é uma nova estrutura: é apenas a estrutura elementar aplicada. Na verdade, as etapas da dialética da experiência da consciência - consciência (imediata) / entendimento / auto-consciência / razão - ocorrem novamente na articulação das formas ou configurações do espírito e da religião. Este é um modo de pensar ou plano de articulação que é absolutamente característico da filosofia de Hegel: o fim de um movimento dialético é o princípio de um novo movimento, e as estruturas do primeiro movimento retornam no segundo movimento. Esta questão importante será abordada mais adequadamentena Parte 2 do artigo.

\subsubsection{A Fenomenologia como uma ciência filosófica}

O método dialético de Hegel na Fenomenologianão podeser adequadamente descrito e avaliado aqui. Mas outro tópico intimamente relacionado deve ser brevemente abordado: o status filosófico da Fenomenologia. Na terminologia de Hegel trata-se da questão se a Fenomenologia é ou não uma ciência (filosófica). Como é bem sabido, esta é uma questão que de longa data tem sido muito discutida.

\footnotetext{
Bewußtseyn anzufangen und die Dialektik desselben bis zum Standpunkte der philosophischen Wissenschaft zu entwickeln, dessen Nothwendigkeit durch diesen Fortgang aufgezeigt wird. Es konnte hiefür aber nicht beim Formellen des bloßen Bewußtseyns stehen geblieben werden; denn der Standpunkt des philosophischen Wissens ist in sich zugleich der gehaltvollste und concreteste; somit als Resultat hervorgehend, setzte er auch die concreten Gestalten des Bewußtseyns, wie z. B. der Moral, Sittlichkeit, Kunst, Religion voraus. Die Entwickelung des Gehalts, der Gegenstände eigenthümlicher Theile der philosophischen Wissenschaft, fällt daher zugleich in jene zunächst nur auf das Formelle beschränkt scheinende Entwickelung des Bewußtseyns; hinter dessen Rücken jene Entwickelung sozusagen vorgehen muss, insofern sich der Inhalt als das Ansich zum Bewußtseyn verhält. Die Darstellung wird dadurch verwickelter, und was den concreten Theilen angehört, fällt schon zum Theil mit in jene Einleitung. (Enz. § 25, nota)

15 die Gewissheit, alle Realität zu sein. Dieses Ansich oder diese Realität ist aber ein noch durchaus allgemeines, die reine Abstraktion der Realität. (PhG 160 [134])
} 
Por um lado, Hegel caracteriza a Fenomenologia como sendo a introdução e a justificação do ponto de vista fil osófico que el e chama simplesmente de "ciência", e enfatiza que, porque "conceito e objeto, o padrão da medida e o que deve ser testado, estão presentes na consciência mesma, uma achega [Zutat] de nossa parte [von uns] se torna supérflua" (Fenom. I 70). ${ }^{16}$ "Von uns" significa aqui "de nós, os teoristas, os expositores".

Por outro lado, Hegel diz explicitamente que a própria Fenomenologia não pode ser simplesmente entendida apontando unicamente para esse aspecto. Outro aspecto ou fator é requerido que deixa claro que a Fenomenologia é "já uma ciência (schon Wissenschaft)" (Fenom. I 72; PhG 68 [61]). E então introduz uma tese metodologicamente absolutamente fundamental: "Esta consideração da Coisa é uma achega de nossa parte" (Fenom. Ibidem). ${ }^{17}$

Este status metódico-filosófico bifronte da Fenomenologia é de central importância em relação à tentativa de reconsiderar o valor filosófico do grande projeto da obra de Hegel, como se verá na Parte 2 (cf. abaixo 2.1.3. [1]).

\subsubsection{O resultado da Fenomenologia: qual é exatamente a di- mensão lógica (no sentido de Hegel)?}

Uma (re)avaliação interpretativa e crítica bem fundamentada da idéia e da estrutura da Fenomenologia gira fundamental mente em torno do que Hegel considera como o objetivo da obra: ser a introdução da consciência natural no "saber absoluto" ou na "ciência (Wissenschaft)" ou no "ponto de vista da ciência filosófica ou do saber filosófico", sendo que Hegel entende "introdução" como "a justificação (do conceito de ciência)" (Veja-se WL, Introdução, I 29). Mas exatamente o que é "ciência” para Hegel, o queé “o ponto de vista da ciência filosófica ou do saber filosófico", etc.? Hegel entende "ciência" no sentido de "ciência filosófica". Se se leva em conta o conjunto da filosofia de Hegel, aparece claramente que é preciso distinguir um sentido estrito de um sentido amplo da expressão "ciência (filosófica)". No sentido estrito, "ciência" se identifica com "a ciência da lógica (no sentido hegeliano de "lógica")"; no sentido amplo, "ciência" abarca a totalidade da filosofia (do saber filosófico), portanto, o saber manifestado em todas as disciplinas filosóficas. Para uma reavaliação sistemática ${ }_{1+2}$ da Fenomenologia, bastará uma análise minuciosa do sentido estrito.

[1] Quanto ao sentido estrito de "ciência", é preciso introduzir uma importante distinção: a distinção entre a dimensão ou o ponto de vista do saber filosófico e a ciência da lógica como tal. Negativamente, o ponto de vista do saber filosófico é o resultado da supressão da distinção ou oposição entre

\footnotetext{
${ }^{16}$ der Begriff und Gegenstand, der Maßstab und das zu Prüfende, in dem Bewusstsein selbst vorhanden sind, wird eine Zutat von uns überflüssig. (PhG 65 [59])

17 Diese Betrachtung der Sache ist unsere Zutat. (PhG 67 [61])
} 
(auto-)consciência e objeto ou "o sujeito e o objeto". Talvez a melhor caracterização de Hegel deste aspecto negativo do ponto de vista ou dimensão do saber filosófico se encontre no início de $A$ Ciência da Lógica na seção intitulada Divisão Geral da Lógica. Aí ele explica seu ponto de vista especulativo criticando o ponto de vista transcendental de Kant. O resultado da superação da oposição da consciência ao seu objeto, i.e. a dimensão, livre de tal oposição, é chamada por Hegel "pensar [ou pensamento] como tal (Denken als solches) ou "pensar absoluto (im absoluten Sinne)".

[2\} Como se dá a identificação do "pensar (absoluto)" como a dimensão lógica bem entendida (no sentido de Hegel)? A questão é fundamental não só para a interpretação da Ciência da Lógica, mas também da Fenomenlogia.

[i] Em geral, Hegel aceita como uma real idade que a dimensão do puro saber é simplesmente idêntica à dimensão da lógica (no seu sentido), mas em algumas passagens ele fornece pelo menos algumas insinuações de como ele explicaria isso. Por exemplo, no capítulo introdutório da Lógica do Ser, intitulado Com que deve começar a Ciência?, ele escreve:

O saber puro, enquanto convergiu nesta unidade [i.e. a unidade, que constitui o resultado da Fenomenologia], superou qualquer relação a outro e à mediação; ele é o indistinto. Esta indistinção deixa por isso mesmo de ser saber. A presenta-se apenas como simples imediatez. (Ciência da Lógica I $54)^{18}$

A identificação feita por Hegel entre puro pensar e dimensão lógica passa por diversas etapas: o puro pensar é caracterizado primeiramente como a dimensão da superação da oposição entre a consciência e seu objeto, esta dimensão é caracterizada então como unidade; esta unidade é caracterizada como indistinta; e esta indistinção é caracterizada como simples imediação. Mas então, surpreendentemente, Hegel caracteriza a simples imediação como puro ser (reines Sein). A dimensão lógica hegeliana é a dimensão das (mas exatamente: de todas as) determinações do pensar (Denkbestimmungen) e "ser" é a primeira determinação - uma determinação curiosa, porque ela consiste unicamente em ser "o indeterminado imediato". Qual é então o caráter distintivo da concepção hegeliana de ser e de lógica?

Não pode haver dúvida que a dimensão lógica (na terminologia de Hegel: o "elemento" lógico) é concebida com referência à relação entre a consciência (ou o sujeito) e seu correlativo (o objeto); de acordo com Hegel há uma perfeita correspondência entre as formas fenomenológicas ou Gestalten da

\footnotetext{
18 Das reine Wissen, als in dies Einheit [d. h., die Einheit, als das Resultat der Phänomenologie] zusammengegangen, hat alle Beziehung auf ein Anderes und auf Vermittelung aufgehoben; es ist das Unterschiedslose; dieses Unterschiedslose hört somit selbst auf, Wissen zu sein; es ist nur einfache Unmittelbarkeit vorhanden. (WL I 54)
} 
relação entre a consciência e seu correlativo, de um lado, eas determinações do pensar, de outro. ${ }^{19}$ Mas o que significa "correspondência" aqui? Hegel diz o seguinte:

[É preciso] notar que aquelas figuras da intuição, representação e outras semelhantes pertencem ao espírito consciente de si, o qual como tal não é considerado na Ciência da Lógica. As determinações puras de ser, essência e conceito constituem, na verdade, também o fundamento e a estrutura interna simples das formas do espírito: o espírito enquanto intuitivo bem como enquanto consciência sensível está na determinidade do ser imediato, assim como o espírito enquanto representativo tanto como enquanto consciência perceptiva se elevou do ser ao nível da essência ou da reflexão. No entanto, estas figuras concretas interessam tão pouco à Ciência da Lógica como as formas concretas que assumem as determinações lógicas na natureza. (Ciência da Lógica II 223-224; itálicas do autor)20

Certamente, segundo Hegel as determinações lógicas ocorrem ou podem ser encontradas em todas as esferas da realidade - na natureza, na esfera da vida, e na esfera do espírito. De uma perspectiva interpretativa, esta idéia geral de correspondência é, sem dúvida, correta. Mas ela éinsuficiente para explicar a relação real entre lógica e fenomenologia e, mais particularmente, explicar como, segundo Hegel, a dimensão lógica deve ser entendida. Ela articula apenas a estrutura superficial, não a estrutura profunda.

\footnotetext{
${ }_{19}$ Veja-se Darstellung, Methode und Struktur, p. 173-223. Veja-se também a seguinte passagem da Fenomenologia:

Wenn in der Phänomenologie des Geistes jedes Moment der Unterschied des Wissens und der Wahrheit, und die Bewegung ist, in welcher er sich aufhebt, so enthält dagegen die Wissenschaft diesen Unterschied und dessen Aufheben nicht, sondern indem das Moment die Form des Begriffs hat, vereinigt es die gegenständliche Form der Wahrheit und des wissenden Selbsts in unmittelbarer Einheit. Das Moment tritt nicht als diese Bewegung auf, aus dem Bewusstseyn oder der Vorstellung in das Selbstbewusstseyn und umgekehrt herüber und hinüber zu gehen, sondern seine reine von seiner Erscheinung im Bewusstseyn befreite Gestalt, der reine Begriff, und dessen Fortbewegung hängt allein an seiner reinen Bestimmtheit.

Umgekehrt entspricht jedem abstracten Momente der Wissenschaft eine Gestalt des erscheinenden Geistes überhaupt. Wie der daseyende Geist nicht reicher ist, als sie, so ist er in seinem Inhalte auch nicht ärmer. Die reinen Begriffe der Wissenschaft in dieser Form von Gestalten des Bewusstseyns zu erkennen, macht die Seite ihrer Realität aus, nach welcher ihr Wesen, der Begriff, der in ihr in seiner einfachen Vermittlung als Denken gesetzt ist, die Momente dieser Vermittlung auseinanderschlägt und nach dem innern Gegensatze sich darstellt. (PhG 528-529 [432]).

${ }^{20}$ [Es ist] zu bemerken, dass jene Gestalten von Anschauung, Vorstellung und dergleichen dem selbstbewussten Geiste angehören, der als solcher nicht in der logischen Wissenschaft betrachtet wird. Die reinen Bestimmungen von Sein, Wesen und Begriff machen zwar auch die Grundlage und das innere einfache Gerüste der Formen des Geistes aus; der Geist als anschauend, ebenso als sinnliches Bewusstsein ist in der Bestimmtheit des unmittelbaren Seins, so wie der Geist als vorstellend, wie auch als wahrnehmendes Bewusstsein sich vom Sein auf die Stufe des Wesens oder der Reflexion erhoben hat. Allein diese konkreten Gestalten gehen die logische Wissenschaft so wenig an als die konkreten Formen, welche die logischen Bestimmungen in der Natur annehmen. (WL II 223-224; itálicas do autor)
} 
A fim de entender a estrutura profunda da dimensão lógica, é preciso perceber que ela possui uma afinidade absolutamente estreita e próxima com as formas ou Gestalten da manifestação do espírito, i.e. com as Gestalten do processo fenomenológico. Isso se torna claro quando se põe a seguinte questão: Há uma chave para orientar a descoberta - ou mais exatamente, segundo Hegel, a derivação - de cada determinação lógica (i.e. de cada determinação do pensar), a partir da precedente, sendo que o ser constitui o primeiro membro desta cadeia? De fato, existe tal chave ou guia e ela é o fator essencial que determina fundamentalmente o status e o sentido da concepção hegeliana da lógica. Na Introdução da Ciência da Lógica Hegel caracteriza este fator da seguinte forma:

O conceito da Lógica [...] foi dado na Introdução como resultado de uma ciência que se encontra mais além, de tal modo que aqui foi apresentado, por sua vez, como uma pressuposição. A Lógica se definiu, por conseguinte, como a ciência do puro pensar, que tem como seu princípio o saber puro e que assim é uma unidade não abstrata, mas concreta e viva, já que nela é, como superada a oposi ção própria da consciência entre um ente subjetivo para si e um segundo tal ente, um ente objetivo, e o ser é conhecido como puro conceito em si mesmo e o puro conceito como o verdadeiro ser. Tais são, por conseguinte, os dois momentos, que são contidos no momento lógico. Mas eles são conhecidos agora como sendo inseparáveis, não, como na consciência, cada um também como sendo para si. No entanto, uma vez que, por isso, eles ao mesmo tempo são conhecidos como distintos (contudo, não sendo para si), sua unidade não é abstrata, morta, imóvel, mas concreta. (Ciência da Lóg. I 42-43; as itálicas são do autor)21

O que Hegel diz neste texto é da maior importância para a compreensão tanto do processo fenomenológico como do lógico. Pode-se dizer: as formas fenomenológicas ou Gestalten e as determinações lógicas (que Ihes correspondem) são as mesmas, exceto quanto ao fato que os "momentos (Momente)" que constituem tanto as formas ou Gestalten fenomenológicas como as determinações lógicas, possuem diferentes maneiras de manifestação e apresentação: elas aparecem na esfera fenomenológica "tendo cada uma um ser separado", ao passo que na dimensão lógica elas "estão con-

\footnotetext{
${ }^{21}$ Der Begriff der Logik [...] selbst ist in der Einleitung als das Resultat einer jenseits liegenden Wissenschaft, damit hier zugleich als eine Voraussetzung angegeben worden. Die Logik bestimmte sich danach als die Wissenschaft des reinen Denkens, die zu ihrem Prinzip das reine Wissen habe, die nicht abstrakte, sondern dadurch konkrete lebendige Einheit, dass in ihr der Gegensatz des Bewusstseins von einem subjektiv für sich Seienden und einem zweiten solchen Seienden, einem Objektiven, als überwunden, und das Sein als reiner Begriff an sich selbst, und der reine Begriff als das wahrhafte Sein gewusst wird. Dies sind sonach die beiden Momente, welche im Logischen enthalten sind: Aber sie werden nun als untrennbar seiend gewusst, nicht wie im Bewusstsein jedes auch als für sich seiend; dadurch allein, dass sie zugleich als unterschiedene (jedoch nicht für sich seiende) gewusst werden, ist ihre Einheit nicht abstract, tot, unbewegend, sondern konkret. (WL I 42-43; as itálicas sãodo autor)
} 
tidas" de tal maneira que "são conhecidas como sendo inseparáveis". O caráter espeć́fico da dimensão lógica reside no fato de que nela os momentos da relação de oposição são articulados primeiramente em sua unidade e, só em seguida, como puras formas do pensar. "Unidade" e "pureza" são os dois conceitos que Hegel usa geralmente quando tenta explicar como entende a dimensão lógica. Mas esses conceitos, por sua vez, necessitam de ulterior explicação.

[ii] É extremamente difícil atribuir um sentido viável à caracterização de Hegel da idéia fundamental subjacente à sua concepção da lógica. O procedimento talvez mais promissor é o recurso ao conceito de estrutura. Intuitivamente, o conceito de estrutura pode ser definido como uma interconexão ou inter-relação diferenciada e ordenada de elementos ou partes ou aspectos de uma entidade, uma região, um processo, etc. Estrutura, neste sentido, é um conceito básico ou um fator básico em qualquer área teorética. No sentido matemático amplo, uma estrutura é uma coleção ou um n-múltiplo, que consiste de elementos (objetos, itens, entidades de qualquer espécie) e relações (em sentido amplo, que inclui funções e operações) entre esses elementos. ${ }^{22}$

Uma reavaliação interpretativa da concepção hegeliana das determinações do pensar deveria explicá-las como sendo uma forma especial de estruturas. elas são as estruturas que têm como elementos (i.e. como itens numa região ou no universo) os dois opostos: (1) consciência e (2) seu objeto, e que especificam as relações que vigoram entre esses elementos. Quando Hegel diz: "... a dita unidade permanece o elemento" 23 e "as distinções ou a divisão e o desenvolvimento não mais se originam fora desse elemento", ele está tentando explicar o que ele chama a "pureza" das determinações lógicas (do pensar). Para compreender isso, éimportante distinguir um sentido abstrato e um sentido concreto de "estrutura". ${ }^{24}$

No sentido concreto, estrutura é o todo complexo que consiste de (um conjunto de) "elementos/ itens/ entidades" e (de um conjunto) de relações entre eles. No sentido abstrato ou puro, estrutura consiste apenas em (um conjunto de) relações. Na Ciência da Lógica as "determinações do pensar (Denkbestimmungen)" devem ser entendidas como sendo "estruturas abstratas ou puras"; elas são configurações ou relações sem a tematização explícita dos elementos/ itens/ entidades que constituem o conjunto básico, sem a tematização explícita das Gestalten da consciência (e seus objetos).

${ }^{22}$ Veja-se o livro do autor: Ser e estrutura. Um quadro referencial para uma filosofia sistemática. São Leopoldo: Editora Unisinos, 2008, p. 34ss.

${ }^{23}$ Convém enfatizar que em tais textos "elementos" não tem o significado que essa expressão tem na matemática. O termo "elementos" nos escritos de Hegel significa simplesmente "dimensões", "regiões".

${ }^{24}$ Cf. Ser e estrutura, 35 ss. 
Uma ilustração gráfica pode ser útil para esclarecer o ponto central da filosofia de Hegel.

\section{ILUSTRAÇÃO GRÁFICA das CORRESPONDÊNCIAS ESTRUTURAIS entre os PROCESSOS DIALÉTICOS na FENOMENOLOGLA e na LOGICA de HEGEL}

\section{DIMENSÃO FENOMENOLÓGICA}

Símbolos

$\overbrace{C-\longrightarrow \supset}=$ figura de consciência

$\overbrace{==}$ = identidade dos dois relata (dos dois polos) da relação fenomenológica $=$ autoidentidade do sujeito - da autoconsciência - da razâo do espirito - do saber absoluto

$\curvearrowright=$ progresso/avanço dialético fenomenológico

Processo

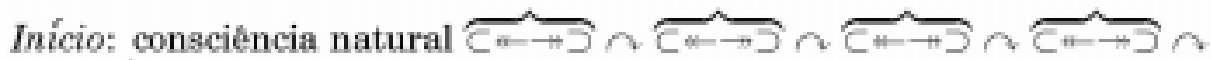

... $\overbrace{=\supset}$ Resultado: autoconsciência - razáo - espírito - saber absoluto

\section{DIMENSÃO LÓGICA}

Símbolos

$\ominus$ = estrutura logica pura ("determinaçáo do pensamento")

$\ominus=$ autoidentidade da estrutura lógica pura (da "determinaçâo do pensamento")

$q$ = progresso/avanço dialético lógico

Processo

Inicio: Ser $\ominus \uparrow, \ominus \uparrow, \ominus \uparrow, \ominus \uparrow, \ominus \uparrow, \ominus \uparrow \ominus \uparrow \uparrow, ., \ominus$ Resultado: Idéia absoluta

3. DIMENSÃ̃ FENOMENOLÓGICA-LÓGICA

Simbolo

$\cong=$ isomorfismo de estruturas

Processo

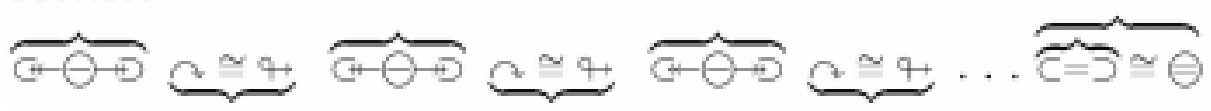




\subsection{O lugar da Fenomenologia no Sistema de Filosofia de Hegel na maturidade}

Antes de apresentar a prometida reavaliação crítica da Fenomenologia, é preciso introduzir algumas observações a respeito do lugar desta obra no sistema posterior da filosofia de Hegel. Para determinar esse lugar, quatro aspectos ou fatores devem ser considerados.

Em primeiro lugar, em algumas passagens de suas obras posteriores $\mathrm{H}$ egel refere-se explicitamente à Fenomenologia. Duas das mais importantes passagens encontram-se na Introdução à Ciência da Lógica. A outra é a longa nota (citada acima) ao § 25 da Enciclopédia. Os dois textos na Introdução são os mais importantes.

Na Fenomenlogia do Espírito [...] expus a consciência no movimento progressivo desde a primeira oposição imediata entre ela e o objeto até o saber absoluto. Este caminho passa por todas as formas da relação da consciência ao objeto e tem como resultado o conceito da ciência. Este conceito, portanto, não necessita aqui qualquer justificação (prescindindo do fato que ele emerge no interior da própria Lógica), já que a recebeu na Fenomenologia. $\mathrm{Na}$ verdade, ele não é capaz de qualquer outra justificação a não ser esta sua produção por obra da consciência, pois nele se convertem todas as figuras próprias dela como na [sua] verdade. - Uma fundamentação racional ou um esclarecimento do conceito da ciência pode no máximo conseguir introduzi-lo perante a representação e com isso proporcionar-lhe um conhecimento histórico. Mas uma definição da ciência ou mais precisamente da Lógica tem sua demonstração tão somente na necessidade de sua emergência. (Ciência da Lóg. I 29-30)25

É significativo que Hegel sempre afirma que a Fenomenologiaé a introdução e a justificação do ponto de vista da ciência filosófica, mas nunca mostra exatamente como isso deveser concebido, i.e. como a Fenomenologia, suposta esta caracterização de seu status, integra-se na concepção sistemática da fil osofia de sua maturidade. Suas declarações (parcial mente citadas) acerca da Fenomenologia parecem ser uma espécie de reminiscência de sua obra mais antiga.

25 In der Phänomenologie des Geistes [...] habe ich das Bewusstsein in seiner Fortbewegung von dem ersten unmittel baren Gegensatz seiner und des Gegenstandes bis zum absoluten Wissen dargestellt. Dieser Weg geht durch alle Formen des Verhältnisses des Bewusstseins zum Objekte durch und hat den Begriff der Wissenschaft zu seinem Resultate. Dieser Begriff bedarf also (abgesehen davon, dass er innerhalb der Logik selbst hervorgeht) hier keener Rechtfertigung, weil er sie daselbst erhalten hat; und er ist keiner andern Rechtfertigung fähig als nur dieser Hervorbringung desselben durch das Bewusstsein, dem sich seine eignen Gestalten alle in denselben als in die Wahrheit auflösen. -- Eine räsonnierende Begründung oder Erläuterung des Begriffs der Wissenschaft kann zum höchsten dies leisten, dass er vor die Vorstellung gebracht und seine historische Kenntnis davon bewirkt werde; aber eine Definition der Wissenschaft oder näher der Logik hat ihren Beweis allein in jener Notwendigkeit ihres Hervorgangs." (WL I 29-30) 
Em segundo lugar, a conjectura há pouco expressa parece ser confirmada por uma passagem extremamente importante, que tem sido quase completamente negligenciada pelos intérpretes da filosofia de Hegel. Num texto que foi acrescentado à segunda edição da Ciência da Lógica na seção introdutória intitulada Com que deve começar a Ciência?, ${ }^{26} \mathrm{Hegel}$ escreve o seguinte:

Aqui [i.e. na Ciência da Lógica] o iniciante é o ser apresentado como o que surge por mediação, e, na verdade, por uma tal mediação que é ao mesmo tempo suprassunção de si mesmo; com a pressuposição do puro saber qual resultado do saber finito, ou seja, da consciência. Mas uma vez que não se deve fazer nenhuma pressuposição, assumindo o próprio início imediatamente, ele se determina somente pelo fato de que deve ser o início da Lógica do pensar para si. Há somente a resolução, que se pode até considerar arbitrária, de querer levar em conta apenas o pensar como tal. (Ciência da Lóg. I 54; as itálicas não se encontram no original) ${ }^{27}$

Aqui Hegel articula a possibilidade de um começo imediato da Ciência da Lógica, um começo isento de qualquer pressuposto: a Ciência da Lógica começaria com a consideração do pensar como tal, portanto, sem a mediação do caminho fenomenológico para a elevação da consciência à dimensão do pensar como tal.

Em terceiro lugar, um suporte adicional à conjectura que os comentários posteriores de Hegel sobre a Fenomenologia têm o caráter de reminiscência, é fornecido pelo fato que na Enciclopédia os conteúdos da primeira parte (a parte "elementar") da Fenomenologia foram integrados em um contexto sistemático completamente diferente. Eles constituem a segunda sub-seção do "Espírito subjetivo", que é a primeira seção da terceira parte do sistema ("A Filosofia do Espírito"). Não há qualquer menção da Fenomenologia de 1807 nesta sub-seção. Os conteúdos da exposição na Enciclopédia correspondem de perto aos da Fenomenologia, mas o status filosófico é inteiramente diferente.

Em quarto lugar, o livro do autor Darstellung, Methode und Struktur ${ }^{28}$ mostra que a única maneira de atribuir à Fenomenologia - ou mais exatamente: não necessariamente ao livro, mas à idéia fundamental da concepção

\footnotetext{
26 Provavelmente Hegel escreveu este texto nos últimos anos de sua vida.

27 Hier [d. h.. in der Wissenschaft der Logik] ist das Sein das Anfangende, als durch Vermittlung, und zwar durch sie, welche zugleich Aufheben ihrer selbst ist, entstanden dargestellt; mit der Voraussetzung des reinen Wissens als des Resultats des endlichen Wissens, des Bewusstseins. Soll aber keine Voraussetzung gemacht, der Anfang selbst unmittelbar genommen werden, so bestimmt er sich nur dadurch, dass es der Anfang der Logik, des Denkens für sich, sein soll. Nur der Entschluss, den man auch für eine Willkür ansehen kann, nämlich dass man das Denken als solches betrachten wolle, ist vorhanden. (WL I 54; as itálicas não se encontram no original) ${ }^{28}$ Cf. Investigação D, seção III (pp. 308-333, especialmente 322-333).
} 
proposta no livro - um lugar coerente e inteligível no sistema filosófico da maturidade é reinterpretar e reavaliar a famosa doutrina dos três silogismos sistemáticos no fim da Enciclopédia ( $\S \S 575-577)$. Os três silogismos articulam a "conexão conclusiva" (Zusammenschluss) das três dimensões fundamentais: Lógica - Natureza - Espírito:

A primeira aparição constitui o silogismo que tem o lógico por fundamento, enquanto ponto de partida, e a natureza como termo médio, que conclui integrando o espírito com ele mesmo (Encicl. § 575) ${ }^{29}$

Segundo a interpretação do autor, este silogismo articula a arquitetônica sistemática do Sistema como é exposto na Enciclopédia, que é dividida em três partes: I. Ciência da Lógica, II. Filosofia da Natureza, III. Filosofia do Espírito. O “termo médio" deste silogismo é, portanto, a natureza.

Mas o termo médio do segundo silogismo é o espírito:

Esta aparição [do conceito] é suprassumida no segundo silogismo, porquanto esse é já o ponto de vista do próprio espírito, que é o mediador do processo: pressupõe a natureza e conclui integrando-a com o lógico. É o silogismo da reflexão espiritual na idéia: a ciência aparece como um conhe cer subjetivo, que tem por fim a liberdade e é, em si mesmo, o caminho pelo qual ela mesma se produz. (Encicl. § 576) ${ }^{30}$

Esta éuma excel ente descrição da dimensão ou perspectiva fenomenológica, i.e. o todo da realidade (i.e. todos os fenômenos, dados, tópicos, domínios, etc.) é "visto" ou "articulado" como o conjunto da experiência:

[...] deve-se dizer que nada é sabido que não esteja na experiência, ou como também se exprime a mesma coisa - que não esteja presente como verdade sentida, como Eterno interiormente revelado, como o sagrado em que se crê, ou quaisquer outras expressões que sejam empregadas. Com efeito, a experiência é exatamente isto: que o conteúdo - e ele é o espírito - seja em si substância, e assim, objeto da consciência. Mas essa substância, que é o espírito, é o seu vir-a-ser para o que ele é em si; e só como esse vir-a-ser refletindo-se sobre si mesmo ele é em si, em verdade, o espírito. O espírito é em si o movimento que é o conhecer, - a transformação desse Em-si no Para-si, da substância no sujeito, do objeto da consciência em objeto da consciência-desi, isto é, em objeto igualmente suprassumido, ou

${ }^{29}$ Die erste Erscheinung macht der Schluss aus, welcher das Logische zum Grunde als Ausgangspunkt und die Natur zur Mitte, die den Geist mit demselben zusammenschließt. (Enz. § 575)

${ }^{30}$ Diese Erscheinung [des Begriffs] ist im zweiten Schlusse insoweit aufgehoben, als dieser bereits der Standpunkt des Geistes selbst ist, welcher das Vermittelnde des Prozesses ist, die Natur voraussetzt und sie mit dem Logischen zusammenschließt. Es ist der Schluss der geistigen Reflexion in der Idee; die Wissenschaft erscheint als ein subjektives Erkennen, dessen Zweck die Freiheit und es selbst der Weg ist, sich dieselbe hervorzubringen. (Enz. § 576) 
seja, no conceito. Esse movimento é o círculo que retorna sobre si, que pressupõe seu começo e que só o atinge no fim. (Fenom. II 215) (11 $^{31}$

De acordo com o segundo silogismo a dimensão fenomenológica, assim entendida, torna-se a perspectiva determinante na apresentação do sistema. O Hegel "sistemático" parece ter assumido que esta obra de 1807 poderia ser vista como uma tal apresentação, certamente no pressuposto de que duas importantes correções ou modificações são levadas em conta: primeiramente, o status sistemático da obra, como sendo a apresentação da dimensão fenomenológica do todo da realidade (ou, segundo Hegel, do todo do espírito), deveria ser explicitado, ou pelo menos tornado mais explícito desde o começo; em segundo lugar,os detalhes da exposição deveriam ser submetidos a maiores modificações.

\section{Este status da dimensão e apresentação fenomenológica do Sistema pode ser mais bem compreendido se consideramos o terceiro silogismo:}

O terceiro silogismo é a idéia da filosofia, que tem a razão, enquanto saber de si, o absolutamene universal, por seu termo médio, que se cinde em espírito e natureza, ao fazer do espírito a pressuposição, enquanto processo da atividade subjetiva da idéia, e da natureza o extremo universal, enquanto processo da idéia sendo em si objetivamente. O julgar a si da idéia nas duas aparições [...] as determina como manifestações suas (da razão, enquanto saber de si) e o que nela se concilia é que a natureza da Coisa o conceito - é o que se movimenta progressivamente e se desenvolve; e esse movimento é igualmente a atividade do conhecer, a idéia eterna sendo em si e para si, que eternamente se atua, engendra e desfruta como espírito absoluto. (Encicl. § 577) 32

\footnotetext{
${ }^{31}$ Es muss [...] gesagt werden, dass nichts gewusst wird, was nicht in der Erfahrung ist, oder wie dasselbe auch ausgedrückt wird, was nicht als gefühlte Wahrheit, als innerlich geoffenbartes Ewiges, als geglaubtes Heiliges, oder welche Ausdrücke sonst gebraucht werden, - vorhanden ist. Denn die Erfahrung ist ebendiß, dass der Inhalt - und er ist der Geist - an sich, Substanz und also Gegenstand des Bewußtseyns ist. Diese Substanz aber, die der Geist ist, ist das Werden seiner zu dem, was er an sich ist; und erst als diß sich in sich reflectirende Werden ist er an sich in Wahrheit der Geist. Er ist an sich die Bewegung, die das Erkennen ist, - die Verwandlung jenes Ansichs in das Fürsich, der Substanz in das Subject, des Gegenstands des Bewußtseyns in Gegenstand des Selbstbewußtseyns, d. h. in ebensosehr aufgehobnen Gegenstand, oder in den Begriff. Sie ist der in sich zurückgehende Kreis, der seinen Anfang voraussetzt, und inn nur im Ende erreicht. (PhG 525 [429]).

32 Der dritte Schluss ist die Idee der Philosophie, welche die sich wissende Vernunft, das Absolut-

Allgemeine zu ihrer Mitte hat, die sich in Geist und Natur entzweit, jenen zur Voraussetzung als den Prozess der subjektiven Tätigkeit der I dee und diese zum allgemeinen Extreme macht, als den Prozess der an sich, objektiv, seienden Idee. Das Sich-Urteilen der Idee in die beiden Erscheinungen [...] bestimmt denselben als ihre (der sich wissenden Vernunft) Manifestationen, und es vereinigt sich in ihr, dass die Natur der Sache, der Begriff, es ist, die sich fortbewegt und entwickelt, und diese Bewegung ebensosehr die Tätigkeit des Erkennens ist, die ewige an und für sich seiende Idee sich ewig als absoluter Geist betätigt, erzeugt und genießt. (Enz. § 577)
} 
Hegel nunca tentou articular uma tal "apresentação absoluta" do Sistema. Há boas razões para pensar que suas Vorlesungen (cursos) sobre a Filosofia da Religião, da História, da Estética, etc. poderiam e deveriam ser entendidas como tendo o status de fragmentos dessa "absoluta apresentação". ${ }^{33}$

\section{Uma reavaliação critica}

$\mathrm{Na}$ Parte 2 será apresentada uma reavaliação crítica (sistemática ${ }_{1+2}$ ), primeiro da Fenomenologia como tal e, segundo, da Fenomenologia em relação com a filosofia sistemática ${ }_{1+2}$.

\subsection{Problemas levantados pela idéia e estrutura da Fenomenologia como tal}

A penas três aspectos ou questões serão abordados: em primeiro lugar, a relação entre a Fenomenologia e a Ciência da Lógica (2.1.1); em segundo lugar, o ponto de vista do saber/ pensar absoluto e a dimensão da teoreticidade (2.1.2); em terceiro lugar, as obscuridades, deficiências e incoerências da Fenomenologia em relação com o seu método e conteúdo (2.1.3).

\subsubsection{A Fenomenologia e a Ciência da Lógica}

Como a reavaliação interpretativa apresentada na Parte 1 tornou claro, a questão mais importante e, na verdade, decisiva a ser dirigida à Fenomenologia é esta: Como avaliar o objetivo e o resultado do processo fenomenológico, i.e. o saber/ pensar absoluto e/ ou a dimensão lógica (no sentido de Hegel)? Se esta questão não é diretamente posta e respondida, a Fenomenologia permanece uma obra isolada, privada de um status e sentido claro.

Neste contexto, o ponto de vista do pensar/ saber absoluto e a dimensão lógica serão considerados conjuntamente como uma unidade de fato. Afirma-se que el es são al tamente problemáticos e mesmo insustentáveis filosoficamente, porque mal-concebidos.

[1] O ponto de vista do saber/ pensar absoluto e a dimensão lógica não são mais do que a articulação de todo o campo das relações multiformes e multifacetadas entre a consciência ou sujeito (subjetividade) e seu objeto: em termos fenomenológicos "as formas ou Gestalten da consciência" e, em

33 Cf. Darstellung, Methode und Struktur, p. 308-322. 
termos lógicos, as "estruturas puras (abstratas)" correspondentes. Por esta razão, a lógica de Hegel é talvez a forma mais elevada e mais completa da assim-chamada "filosofia da subjetividade". ${ }^{34}$

Sem dúvida, embora Hegel repetidamente indique que há correspondências entre lógica, fenomenologia e o que ele chama de psicologia, ${ }^{35}$ ele nunca mostrou isso de maneira detal hada. Seria preciso acrescentar que a exposição sistemática das determinações do pensar na Ciência da Lógica não se baseia em uma referência explícita a essas correspondências; nessa obra Hegel procede apenas logicamente (no sentido hegeliano). Mas esta não é a última palavra a esse respeito. $\mathrm{Na}$ verdade, não pode haver qualquer dúvida que a arquitetônica geral da Ciência da Lógica condiz exatamente com a arquitetônica geral da dimensão fenomenológica (e psicológica), que se caracteriza $(\mathrm{m})$ pelos muitos graus (Gestalten) de relação entre a consciência e o seu correlativo (o objeto no sentido hegeliano). A trajetória fenomenológica ascendente da consciência natural ao ponto mais alto, razão e/ ou saber absoluto, condiz exatamente com a trajetória lógica ascendente do ser indeterminado até o mais algo ponto lógico, a idéia absoluta. Pode-se falar de uma correspondência geral ou global entre consciência natural / entendimento / (auto-consciência) razão, por um lado, e lógica objetiva / lógica subjetiva, do outro.

A concepção hegeliana da estrutura interna deste processo bidimensional constitui a idéia mais importante subjacente à sua filosofia. No Prefácio da Fenomenologia ele descreve esta visão, numa passagem famosa, como a transição ou trajeto da substância para o sujeito.

Segundo minha concepção - que só deve ser justificada pela apresentação do próprio sistema -, tudo decorre de entender e exprimir o verdadeiro não como substância, mas também, precisamente, como sujeito. (Fenom. I 29). ${ }^{36}$

\footnotetext{
${ }^{34}$ Convém notar que a expressão "filosofia da subjetividade" foi usada nas décadas recentes e é usada hoje, provavelmente sob a influência decisiva de Heidegger, para caracterizar o status fundamental da filosofia desde Descartes. Hegel usa o termo "subjetividade" em um sentido semelhante, especialmente para designar filosofias que são unilaterais, enquanto têm um caráter "subjetivista". Mas Hegel pressupõe um quadro teorético completamente diferente. Por um lado, ele usa o termo "sujeito" em formulações que articulam suas teses mais fundamentais, dizendo, por exemplo, a filosofia tem a tarefa de transformar a substância no sujeito. Neste artigo, a expressão "filosofia da subjetividade", enquanto se refere a Hegel, deve ser entendida no sentido de "filosofia do sujeito" (no sentido hegeliano).

35 Cf. Enciclopédia, §§ 440ss.

${ }^{36}$ Es kömmt nach meiner Einsicht, welche sich durch die Darstellung des Systems selbst rechtfertigen muss, alles darauf an, das Wahre nicht als Substanz, sondern eben so sehr als Subject aufzufassen und auszudrücken. (PhG 13-14 [18])
} 
E em relação à dimensão fenomenológica ele acrescenta a observação:

Ao mesmo tempo, deve-se observar que a substancialidade inclui em si não só o universal ou a imediatez do saber mesmo, mas também aquela imediatez que é o ser, ou a imediatez para o saber. (Ibidem) ${ }^{37}$

[2] Como avaliar esta atitude filosófica em uma perspectiva sistemática ${ }_{1+2}$ ? A esse respeito apenas alguns poucos pontos podem ser abordados.

[i] A tentativa de integrar todos os conceitos fundamentais da metafísica tradicional e da lógica tradicional e, além disso, todos os conceitos encontrados na filosofia transcendental de Kant em um sistema de puras estruturas modeladas na base de pontos ou graus da trajetória da substância ao sujeito, da consciência natural à auto-consciência/ razão e/ ou saber absoluto, é uma tentativa/ programa, que de modo al gum é capaz de fazer justiça ao caráter espeć́fico de muitos desses conceitos tomados como puras estruturas. A obra resultante desse programa, a Ciência da Lógica, é, sob esse aspecto, um amálgama grandioso incoerente e ininteligível de diversos conceitos filosóficos tradicionais. A pretensão de Hegel de ter apresentado um "derivação" rigorosamente sistemática das determinações lógicas do pensar é completamente infundada. Sua forma dialética de argumentação não é de modo al gum conclusiva. Isso foi mostrado pelo autor em diversos escritos e não pode ser repetido aqui. ${ }^{38}$

[ii] O pensar/ saber absoluto é o resultado da superação da oposição entre a consciência e seu correlativo, o objeto. No nível da estrutura elementar da dimensão fenomenológica, o pensar/ saber absoluto é auto-consciência/ razão, e "die Vernunft ist die Gewissheit, alle Realität zu sein" (Fenom. 160 [134]). No nível da estrutura concreta da dimensão fenomenológica a razão é o espírito:

A razão é espírito, quando a certeza de ser toda a realidade se eleva à verdade, e ela é consciente de si mesma como de seu mundo e do mundo como de si mesma. (Fenom. II 7).39

${ }_{37}$ Zugleich ist zu bemerken, dass die Substantialität so sehr das Allgemeine oder die Unmittel barkeit des Wissens selbst, als auch diejenige, welche Sein oder Unmittel barkeit für das Wissen ist, in sich schließt. (Ebd.)

${ }^{38}$ Cf. especialmente os ensaios: "Lässt sich der Begriff der Dialektik klären?", in: J ournal for General Philosophy of Science, 27, 1996, p. 131-165. Reimpresso em: PUNTEL, L. B., Auf der Suche nach dem Gegenstand und dem Theoriestatus der Philosophie. Philosophiegeschichtlich-kritische Studien. Tübingen: Mohr Siebeck, 2007, p. 223-254 [a tradução portuguesa deste volume aparecerá em 2009 ou 2010]; e: "Hegels Wahrheitskonzeption. Kritische Rekonstruktion und eine 'analytische" Alternative, in: Internationales J ahrbuch des Deutschen Idealismus / International Yearbook of German Idealism, Vol. 3, 2005, p. 208-242.

39 Die Vernunft ist Geist, indem die Gewißheit, alle Realität zu seyn, zur Wahrheit erhoben, und sie sich ihrer selbst als ihrer Welt, und der Welt als ihrer selbst bewußt ist. (PhG 288 [238]) 
E na dimensão lógica a "pura estrutura" razão / espírito é aquela "estrutura pura" que Hegel chama "a idéia absoluta" como "identidade da idéia teórica e prática." (WL II 483). Mas ela não é senão a "pura estrutura" do sujeito (subjetividade).

Se a estrutura assim concebida pode ou deve ser considerada a estrutura adequada da subjetividade não será discutido aqui. Para a finalidade deste ensaio outro aspecto da concepção hegeliana de razão/ espírito/ pensar/ saber absoluto é a questão que importa realmente: a razão como "certeza de ser toda a realidade elevada ao nível da verdade"; em outras palavras: a razão como "consciente de si mesma como seu mundo e do mundo como si mesma". Mas esta identidade da razão e da realidade ou mundo é não só altamente problemática; é uma redução idealística da realidade/ mundo/ ser à subjetividade que não faz jus ao status específico do mundo/ realidade/ ser; é uma constrição forçada do mundo/ realidade/ ser aos limites da estrutura da subjetividade. M esmo um ol har superficial sobre a arquitetônica do sistema de Hegel mostra cabal mente o caráter abrangente desta redução ou constrição:

A idéia [...] mostra-se como o pensar pura e simplesmente idêntico a si mesmo e esse, por sua vez, como a atividade de, por si mesmo, contraporse a si mesmo, para ser para si; e de ser nesse outro tão somente junto a si mesmo. Assim a ciência se divide em três partes:

I. A Lógica, a ciência da idéia em si e para si.

II. A Filosofia da Natureza como a ciência da idéia em seu ser-outro.

III. A Filosofia do Espírito como da idéia, que de seu ser-outro retorna a si (Encid. § 18$)^{40}$

É dificilmente aceitável conceber a natureza desse modo. Suas estruturas imensamente específicas são completamente ignoradas e negadas.

[ii] Neste contexto poderá ser instrutivo considerar brevemente a posição de outro grande pensador que é incrivel mente afim a Hegel no que concerne ao modo de proceder, mas diverge radical mente dele quanto à interpretação do resultado. Como Hegel, Heidegger tentou ao Iongo de toda a sua vida superar a perspectiva da transcendência, que se caracteriza pela oposição entre sujeito (subjetividade) (ou (auto-)consciência) e a dimensão dos objetos (ou coisas-em-si). Esta preocupação fica clara em uma passagem de uma

\footnotetext{
${ }^{40}$ Die Idee [...] erweist sich als das schlechthin mit sich identische Denken und dies zugleich als die Tätigkeit, sich selbst, um für sich zu sein, sich gegenüber zu stellen und die in diesem Andern nur bei sich selbst zu sein. So zerfällt die Wissenschaft in die drei Teile:

I. Die Logik, die Wissenschaft der Idee an und für sich,

II. Die Naturphilosophie als die Wissenschaft der Idee in ihrem Anderssein,

III. Die Philosophie des Geistes, als der Idee, die aus ihrem Anderssein in sich zurückkehrt. (Enz. § 18)
} 
carta de Heidegger a Husserl datada de 22 de outubro de 1927. Heidegger se opõe ao modo de proceder de Husserl, enquanto privilegia absolutamente a subjetividade transcendental ( $a$ "dimensão constituinte"), com a seguinte argumentação:

O que constitui não é nada, antes algo que é - embora não no sentido do positivo. Portanto, o problema do ser se refere universalmente tanto ao que constitui como ao que é constituído. ${ }^{41}$

É claro que "ser" aqui não é usado para designar o pólo objetivo contrário à subjetividade ou (auto-)consciência, mas, ao invés, para designar a dimensão que é primordial no sentido que ela abarca tanto a subjetividade ((auto)consciência) como a objetividade (ou ser no sentido objetivo). Pode-se dizer que todo o empenho de Heidegger visou à articulação do sentido dessa dimensão primordial e oniabrangente, i.e. do Ser. Entretanto, é preciso que fique imediatamente claro que o Ser de Heidegger e o ser de Hegel não só não podem ser identificados, mas, ao contrário, diferem de todos os modos possíveis. Perguntar o que éSer no sentido de Hegel significa o mesmo que perguntar como Hegel entende sua dimensão lógica. O "Ser" de Hegel não éa expressão que designa a dimensão que abarca a subjetividade (ou (auto)consciência) e a objetividade, mas é a expressão que designa a própria subjetividade imediata e indeterminada.

A dimensão hegeliana do pensar/ saber absoluto, a dimensão do ser e da idéia absoluta, não é a dimensão primordial que abarca a subjetividade e o ser objetivo no sentido de toda a realidade objetiva. A dimensão genuinamente "absoluta" que abarca ambos os pól os merece plenamente ser chamada a dimensão do ser primordial e originário. A respeito desse ponto fundamental o autor remete a seu livro Estrutura e ser. ${ }^{42}$

\subsubsection{O ponto de vista do pensar/ saber absoluto e a dimensão da teoreticidade}

O ponto central para uma avaliação da Fenomenologia deveria ser o conceito hegeliano de pensar ou saber absoluto. Tudo depende disso. Mas esse conceito é altamente problemático sob muitos aspectos. Para os objetivos desse ensaio um aspecto é de particular importância.

[1] Do que foi dito emerge o que deve ser considerado como a falta mais fundamental do modo hegeliano de pensar: trata-se de sua perspectiva mentalista oniabrangente. A linguagem não desempenha absolutamente quase nenhum papel..$^{43}$ Conseqüentemente, a semântica é simplesmente

\footnotetext{
${ }^{41}$ Em: Husserliana IX (1962), p. 602.

42 Estrutura e ser, capítulo 5, seções 5.2 e 5.3

43 Isso não quer dizer que Hegel não mencione a linguagem. Mas a sua compreensão da linguagem não aborda a questão mais importante: a semântica.
} 
ausente da filosofia de Hegel. O ponto de referência, central e único, para todo o seu programa filosófico é a relação entre a consciência/ sujeito e o objeto, sendo que o sujeito ou subjetividade é o núcleo absoluto de todas as considerações. Mesmo - ou, mais exatamente, especialmente- quando procura de todos os modos superar as inegáveis falhas da filosofia da subjetividade, ele torna-se inteiramente presa da subjetividade como seu ponto central de referência. Na verdade, "determinações do pensar", como ele chama os conceitos lógicos, são "formas puras", i.e. as estruturas puras, ou Gestalten da subjetividade.

A pesar de sua crítica, bem conhecida, da posição de Kant, Hegel declara explicitamente que ele é profundamente devedor da filosofia kantiana. Ele diz:

Kant superou [a] relação extrínseca do entendimento como a faculdade dos conceitos, e do próprio conceito, para o Eu. Uma das intuições mais profundas e corretas, que se encontram na Crítica da razão, consiste em ter reconhecido a unidade, que constitui a essência do conceito, como a unidade originariamente sintética da apercepção, enquanto unidade do Eu penso, ou da auto-consciência. - Esta tese constitui a assim chamada dedução transcendental das categorias; ela foi considerada desde sempre como uma das passagens mais difíceis da filosofia kantiana - sem dúvida, por nenhuma outra razão senão porque ela exige que a mera representação da relação, na qual o Eu e o entendimento ou os conceitos se apresentam como uma coisa e suas propriedades e acidentes, seja ultrapassada em direção ao pensamento. (Ciência da Lóg.II 221) ${ }^{44}$

\footnotetext{
${ }^{44}$ Kant ist über [das] äußerliche Verhältnis des Verstandes als des Vermögens der Begriffe und des Begriffs selbst zum Ich hinausgegangen. Es gehört zu den tiefsten und richtigsten Einsichten, die sich in der Kritik der Vernunft finden, dass die Einheit, die das Wesen des Begriffs ausmacht, als die ursprünglich-synthetische Einheit der Apperzeption, als Einheit des: Ich denke, oder des Selbstbewusstseins erkannt wird. -- Dieser Satz macht die sogenannte transzendentale Deduktion der Kategorie aus; sie hat aber von jeher für eines der schwersten Stücke der Kantischen Philosophie gegolten - wohl aus keinem andern Grunde, als weil sie fordert, dass über die bloße Vorstellung des Verhältnisses, in welchem Ich und der Verstand oder die Begriffe zu einem Ding und seinen Eigenschaften und Akzidenzen stehen, zum Gedanken hinausgegangen werden soll.

O texto completo da Introdução à Lógica Subjetiva na Ciência da Lógica fornece uma visão reveladora das bases da filosofia hegeliana. A continuação da passagem citada diz:

Das Objekt, sagt Kant [...], ist das, in dessen Begriff das Mannigfaltige einer gegebenen Anschauung vereinigt ist. Alle Vereinigung der Vorstellungen erfordert aber Einheit des Bewusstseins in der Synthesis dersel ben. Folglich ist diese Einheit des Bewusstseins dasjenige, das allein die Beziehung der Vorstellungen auf einen Gegenstand, mithin ihre objective Gültigkeit, ausmacht, und worauf selbst die Möglichkeit des Verstands beruht. [...] Die Prinzipien [...] der objektiven Bestimmung der Vorstellungen seien [nach Kant, LBP] allein aus dem Grundsatze der transzendentalen Einheit der Apperzeption abzuleiten. Durch die Kategorien, welche diese objektiven Bestimmungen sind, werde das Mannigfaltige gegebener Vorstellungen so bestimmt, dass es zur Einheit des Bewusstseins gebracht werde. -- Nach dieser Darstellung ist die Einheit
} 
As coisas mudam completamente quando a perspective mentalista é abandonada. Isso acontece quando a linguagem e todo o campo que a rodeia entra decisivamente na cena filosófica e se torna o ponto de referência central. Pressupõe-se aqui, certamente, que a linguagem não é entendida no sentido da "linguagem natural" ou "coloquial", mas no sentido das linguagens "filosóficas/ científicas". ${ }^{45}$ Além disso, admite-se que a semântica da linguagem em questão não é entendida em função de sua pragmática, caso em que a linguagem é interpretada em função do falante como sujeito. A filosofia pragmática da linguagem éguiada pelo slogan, que Robert Brandon assim formulou: "A semântica deve corresponder à pragmática" ${ }^{46} \mathrm{Aqui}$, ao invés, assume-se a posição exatamente oposta: "A pragmática deve corresponder à semântica". Isso significa que os fatores pragmáticos, especialmente o fator "o falante como sujeito", desempenham um papel completamente secundário. A linguagem nesse sentido, por assim dizer, interpreta a si mesma, precisamente pela ocorrência do vocabulário semântico. Para ilustrar brevemente este ponto pode-se citar a famosa caracterização informal do conceito de verdade, feita por A. Tarski:

Uma sentença verdadeira é aquela que diz que a realidade se comporta de tal maneira, e a realidade, de fato, se comporta assim. ${ }^{47}$

des Bewusstseins dasjenige, wodurch etwas nicht bloße Gefühlsbestimmung, Anschauung oder bloße Vorstellung, sondern Objekt ist, welche objective Einheit die Einheit des Ich mit sich selbst ist. -- Das Begreifen eines Gegenstandes besteht in der Tat in nichts anderem, als dass I ch denselben sich zu eigen macht, inn durchdringt und ihn in seine eigene Form, d. i. in die Allgemeinheit, welche unmittelbar Bestimmtheit, oder Bestimmtheit, welche unmittelbar Allgemeinheit ist, bringt. Der Gegenstand in der Anschauung oder auch in der Vorstellung ist noch ein Äußerliches, Fremdes. Durch das Begreifen wird das An- und Fürsichsein, das er im Anschauen und Vorstellen hat, in ein Gesetztsein verwandelt; Ich durchdringt ihn denkend. Wie er aber im Denken ist, so ist er erst an und für sich; wie er in der Anschauung oder Vorstellung ist, ist er Erscheinung; das Denken hebt seine Unmittelbarkeit, mit der er zunächst vor uns kommt, auf und macht so ein Gesetztsein aus ihm; dies sein Gesetztsein aber ist sein An- und Fürsichsein oder seine Objektivität. Diese Objektivität hat der Gegenstand somit im Begriffe, und dieser ist die Einheit des Sel bstbewusstseins, in die er aufgenommen worden; seine Objektivität oder der Begriff ist daher selbst nichts anderes als dieNatur des Selbstbewusstseins, hat keine andere Momente oder Bestimmungen als das Ich selbst. Hiernach rechtfertigt es sich durch einen Hauptsatz der Kantischen Philosophie, dass, um das zuerkennen, was der Begriff sei, an die Natur des Ich erinnert wird. (WL II 221-222; as itálicas são do autor).

${ }^{45}$ Cf. Estrutura e ser, subseção 2.2 .

${ }^{46}$ BRANDOM, Robert B., Making it Explicit Reasoning. Representing, \& Discourse Commitment. Cambridge/Ma, London: Harvard University Press, 1994, p. 83.

47 TARSKI, A., "Der Wahrheitsbegriff in den formalisierten Sprachen [1933]", in: BERKA, K./ KREISER, L. Logik-Texte. Kommentierter Auswahl zur Geschichte der modernen Logik. Darmstadt: Wissenschaftliche Buchgesellschaft, dritte, erweiterte Auflage 1983, p. 445-546; cit. p. 450. Para uma interpretação aprofundada desta passagem, cf. do autor: Grundlagen einer Theorie der Wahrheit. Berlin: de Gruyter, 1990, p. 41-46. Cf. também Estrutura e ser p. 298-301. 
De central importância para o objetivo presente é a frase, "a sentença (não o falante, o sujeito...) diz que..." A semântica nesse sentido é a auto-determinação da própria linguagem. N esta perspectiva a dimensão pragmática, que inclui os sujeitos, os falantes, etc. e todas as suas ações como declarar, afirmar, etc., é completamente ausente.

[2] A esta altura é possível mostrar que a dimensão que Hegel pretendeu atingir, mas que, como se mostrou, não conseguiu alcançar, por causa de sua concentração exclusiva no sujeito (ou na subjetividade) e que ele - a partir dessa perspectiva - denomina a dimensão ou ponto de vista do "pensar/ saber absoluto" pode - de maneira incrivelmente simples - ser alcançada pela simples análise da estrutura das sentenças que constituem as teorias filosóficas. Estas sentenças são indicativas (ou declarativas) e merecem ser chamadas justamente de sentenças teoréticas. Sua estrutura é definida por Wittgenstein, que escreve no Tractatus. "A forma geral da sentença [indicativa, teorética] é: É o caso que assim-eassim" (Tractatus 4.5) Esta formulação é extraordinariamente simples e, ao mesmo tempo, extraordinariamente profunda e importante. Ela revela que o ponto de vista do "pensar/ saber absoluto" é articulado pelo operador "É o caso que..." - o operador teorético - que explícita ou implicitamente precede a sentença.

A fim de alcançar a máxima clareza a respeito do status das sentenças teoréticas, érecomendável, em certos contextos importantes, tornar explícito o operador teorético por meio de um símbolo específico. Nos escritos do autor é usado o símbolo o símbolo '『i)'. A ssim, por exemplo, a sentença “É o caso que a terra gira ao redor do sol" é formalizada como "(i) ö' incorporado.WMF A filosofia como ciência teorética apresenta apenas sentenças teoréticas. É da maior importância sublinhar este fato óbvio porque a filosofia é com freqüência confundida com uma ou outra atividade prática (p.ex. aconselhamento, literatura de ajuda, engajamento político, etc.). No presente contexto o ponto importante é o fato que a estrutura da sentença teorética não faz referência a nada como um sujeito ou falante ou consciência ou algo semelhante. Ela diz simplesmente: Algo é articulado absolutamente. Mas essa circunstância evidencia que qualquer oposição entre a consciência ou sujeito ou falante e seu correlativo (o objeto) está simplesmente "fora de jogo". Estamos no interior da dimensão genuinamente absoluta do pensar ou articular... Torna-se então manifesto que o ponto de vista de Hegel a respeito do "pensar/ saber absoluto" não é um "ponto de vista absoluto" genuíno. Na verdade, éo ponto de vista da subjetividade, que reduziu a si mesma o imenso reino da realidade.

\subsubsection{Obscuridades, deficiências e incoerências da Fenomenologia em relação ao método e conteúdo}

A respeito do método e do conteúdo da Fenomenologia haveria muito a dizer. Neste ensaio apenas três pontos serão abordados. 
[1] De um ponto de vista global um dos problemas mais importantes levantados pela caracterização de seu método pelo próprio Hegel refere-se ao conceito e ao lugar da experiência no processo fenomenológico. Por um lado, Hegel caracteriza a experiência como o "processo dialético que a consciência executa sobre si mesma - sobre seu conhecimento tanto quanto sobre o objeto dele - no sentido que a partir dele surge o novo e verdadeiro objeto" (Fenom. I 71; PhG 66 [60]), "de modo que, uma vez que a própria consciência examina a si mesma, não nos resta, sob este aspecto, senão simplesmente e unicamente olhar [...] Qualquer acréscimo de nossa parte [unsere Zutat] seria supérfluo." (Fenom. I 70; PhG 65 [59]) Por outro lado, Hegel escreve:

Daquele ponto de vista [dialético] [...] mostra-se o novo objeto como vindo-a-ser mediante uma reversão da consciência mesma. Essa consideração da Coisa é uma achega [Zutat] de nossa parte, por meio da qual a série de experiências da consciência se eleva a um processo científico, mas, para a consciência que examinamos, essa consideração não tem lugar. (Fenom.

I 72). ${ }^{48}$

Estas declarações envolvem uma profunda incoerência: se a própria consciência examina a si mesma, realiza a comparação entre ela e o seu objeto, se ambos os pólos dessa relação “estão presentes na consciência que nós contemplamos", isso não pode significar senão que a própria consciência é capaz de real izar e de articular todo o processo de suas experiências. Por que se necessitaria ainda de um fator inteiramente externo, a saber, "nós", os teoristas ou expositores, a fim de articular esse processo?

Mas, se o fator externo é ou deve ser introduzido a fim de explicar o processo na sua totalidade, como ele "se justifica"? É estranho como Hegel, que critica com agudeza outros filósofos, parece não se dar conta que sua admissão do "nós" cria um tremendo problema para ele.

[2] Outro problema relativo tanto ao método como ao conteúdo da Fenomenologia resulta da concepção hegeliana da emergência de um ou do novo "objeto" da consciência. Como concebe Hegel o "objeto"? Há uma profunda obscuridade neste conceito na Fenomenologia. Naturalmente, o primeiro objeto e os demais objetos da consciência não são simplesmente os assim-chamados "objetos do mundo" no sentido normal dessa expressão. Que são eles então? Serão al go como esquemas conceituais ou estruturas teoréticas? De modo algum!

A interpretação mais plausível e coerente parece ser a seguinte: "objeto" na Fenomenologiaé um termo que designa todos os correlativos da consciência

\footnotetext{
${ }^{48}$ In jener [d. h., dialektischen] Ansicht [...] zeigt sich der neue Gegenstand als geworden, durch eine Umkehrung des Bewußtseyns selbst. Diese Betrachtung der Sache ist unsere Zuthat, wodurch sich die Reihe der Erfahrungen des Bewußtseyns zum wissenschaftlichen Gang erhebt, und welche nicht für das Bewußtseyn ist, das wir betrachten. (PhG 67 [61])
} 
em todas as suas etapas ou em todas as Gestalten de sua relação com a dimensão que Hegel chama "o outro". Os correlativos devem ser entendidos como sendo situados ao longo de uma escala na qual o correlativo "objetivo" inferior é o que está mais distante da auto-relação, i.e. da auto-identidade da consciência enquanto sujeito, e na qual o correlativo "objetivo" superior éa própria consciência idêntica a si mesma enquanto sujeito idêntico a si mesmo. O critério para definir que um "objeto" é novo e superior em relação a outro "objeto" é a sua localização superior na escala ou sua proximidade maior ao "objeto" superior, i.e. ao próprio sujeito, chamado de auto-consciência, razão, espírito. O processo termina quando a auto-identidade entre o sujeito/ auto-consciência/ razão/ espírito e o "objeto" é alcançada, i.e. quando o "objeto" do sujeito/ auto-consciência/ razão/ espírito é o sujeito/ auto-consciência/ razão/ espírito.

É claro, portanto, que não tem sentido falar de uma genuína ontologia na Fenomenologia. Poder-seia falar apenas de uma ontologia reducionista radical no sentido que todo o reino dos "objetos reais" ou "seres", é simplesmente reduzido a Gestalten do sujeito/ auto-consciência/ razão/ espírito. É preciso perguntar ainda como esta "redução" deve ser exatamente entendida. Pode-se dizer que os correlativos não são "objetos reais" no sentido normal, mesmo se no processo dialético das experiências da consciência sejam usados para designá-los nomes normalmente empregados para objetos ou regiões de objetos. Mas isso não é exatamente o que o próprio Hegel pretende e defende. Para ele, o "status genuinamente ontológico" dos objetos é justamente o status que corresponde ao "aparecimento (Erscheinung)" do(s) objeto(s) na dimensão fenomenológica. Mais precisamente: desde que cada um dos "aparecimentos" do(s) objeto(s) corresponde a uma determinação lógica (uma "determinação do pensar"), e desde que as determinações lógicas são formas ou etapas ou graus do "conceito" e desde que o "conceito" não é senão "die Sache selbst", i.e. "a coisa real em si mesma", segue-se, segundo Hegel, que não tem qualquer sentido "separar" os "objetos enquanto aparecem ou enquanto fenomenológicos" dos "objetos reais". Eles são uma e a mesma coisa. Mas sua "realidade" ou seu "status ontológico real/ genuíno" é, segundo Hegel, o resultado de sua mensuração pelo "ponto superior", e este, na dimensão fenomenológica, é o sujeito/ auto-consciência/ razão/ espírito e, na dimensão lógica, a idéia absoluta: os "objetos" são simplesmente modos deficientes da idéia absoluta. Isso é exatamente o que Hegel pretende dizer e o que ele apresentou posteriormente quando desenvolveu sua filosofia da natureza, da vida, ou do mundo social, etc.

Mas, desse modo, a "realidade" que não é idêntica como o sujeito/ autoconsciência/ razão/ espírito é simplesmente perdida, ignorada, preterida, omitida, ou "aufgehoben", removida... É inaceitável conceber o imenso reino da realidade dessa maneira 
[3] Um terceiro ponto concerne o método dialético como um método que explica a maneira de originar-se e a emergência do novo objeto. O ponto essencial é o mesmo na Fenomenologia e na Ciência da Lógica: a negação (mais exatamente: a negação da negação) como negação determinada.

O que unicamente se requer, para alcançar o progresso científico - e acerca de cuja simplicíssima compreensão se trata de empenhar-se essencialmente - é o conhecimento da tese lógica, segundo a qual o negativo é igualmente positivo, ou que o que entra em contradição consigo mesmo não se reduz a zero ou ao nada abstrato, mas essencial mente apenas à negação de seu conteúdo particular, ou seja, que tal negação não é toda negação, mas sim a negação daquela Coisa determinada, que se desfaz, e, portanto, uma negação determinada. Em outras palavras: no resultado está contido essencialmente aquilo do qual ele resulta. [...] Uma vez que o resultante, a negação, é negação determinada, ela tem um conteúdo. É um novo conceito, mas um conceito que é superior e mais rico que o precedente. (Ciência da Lóg. I 35-36).49

Na Fenomenologia este "princípio lógico" é aplicado ao tema "concreto" da análise fenomenológica, i.e. à relação entre consciência e objeto:

A série completa das formas da consciência não-real resultará mediante a necessidade do processo e de sua concatenação mesma. Para tornar inteligível esse ponto, podese notar previamente, de maneira geral, que a apresentação da consciência não verdadeira em sua inverdade não é um movimento puramente negativo. Uma opinião assim unilateral [...] é o ceticismo, que vê sempre no resultado somente o puro nada, e abstrai de que esse nada é determinadamente o nada daquilo de que resulta. Porém, o nada, tomado como o nada daquilo donde procede, não é, de fato, senão o verdadeiro resultado. É assim algo determinado e tem um conteúdo. (Fenom. I 67) ${ }^{50}$

49 Das Einzige, um den wissenschaftlichen Fortgang zu gewinnen, - und um dessen ganz einfache Einsicht sich wesentlich zu bemühen ist, - ist die Erkenntnis des logischen Satzes, dass das Negative ebensosehr positiv ist, oder dass das sich Widersprechende sich nicht in Null, in das abstrakte Nichts auflöst, sondern wesentlich nur in die Negation seines besondern Inhalts, oder dass eine solche Negation nicht alle Negation, sondern die Negation der bestimmten Sache, die sich auflöst, somit bestimmte Negation ist, dass also im Resultate wesentlich das enthalten ist, woraus es resultiert. [...] Indem das Resultierende, die Negation, bestimmte Negation ist, hat sie einen Inhalt. Sie ist ein neuer Begriff, aber der höhere, reichere Begriff als der vorhergehende.(WL I 35-36)

${ }^{50}$ Die Vollständigkeit der Formen des nicht realen Bewußtseyns, wird sich durch die Nothwendigkeit des Fortganges und Zusammenhanges selbst ergeben. Um dies begreiflich zu machen, kann im Allgemeinen zum voraus bemerkt werden, daß die Darstellung des nicht wahrhaften Bewußtseyns in seiner Unwahrheit nicht eine bloß negative Bewegung ist. Eine solche einseitige Ansicht [...] ist der Skepticismus, der in dem Resultate nur immer das reine Nichts sieht und davon abstrahirt, dass diß Nichts, bestimmt das Nichts dessen ist, woraus es resultiert. Das Nichts ist aber nur, genommen als das Nichts dessen, woraus es herkömmt, in der That das wahrhafte Resultat; es ist hiemit selbst ein bestimmtes und hat einen Innhalt. (PhG 62 [56-57]) 
Como é bem sabido, esteé o problema fundamental da dialética hegeliana: como explicar a necessidade de avançar da negação da negação de algo (na dimensão lógica, um conceito, na dimensão fenomenológica: uma Gestalt da consciência), para al go positivo, i.e. para um novo conceito e para uma nova Gestalt da consciência, respectivamente? Em outros escritos o autor mostrou de maneira decisiva que este "princípio lógico" é completamente infundado e, portanto, arbitrário. A dialética hegeliana não consegue realizar o que Hegel Ihe atribui. ${ }^{51}$

Mas é digno de menção que há uma diferença significativa entre a dialética da Fenomenologia e a dialética da Ciência da Lógica. Como se mostrou acima, na Fenomenologia Hegel reconhece explicitamente que o processo ou progresso dialético-fenomenológico não pode ser explicado em sua necessidade interna simplesmente apenas a partir da(s) experiência(s) da consciência ou apenas a partir do movimento dialético, "que a consciência exerce em si mesma, tanto em seu saber, como em seu objeto" (Fenom. 73). N ossa contribuição (Zutat), i.e. a contribuição dos teoristas, é requerida como indispensável. Na Ciência da Lógica não há qualquer reconhecimento explícito de Hegel a esse respeito. A admissão de um Zutat da parte de nós, os teoristas, pode explicar até certo ponto o processo da "origem ou emergência (Entstehung) de novo(s) objeto(s) e de nova(s) Gestalt(en) da consciência tanto quanto a "completude" das Gestalten e "a necessidade do avanço e a necessidade da conexão entre el as". Dizemos "até certo ponto", primeiro, porque estas "explicações" levantam um problema fundamental de coerência, como se mostrará mais abaixo; em segundo lugar, porque esta explicação só pode ser entendida em um sentido muito restrito, como demonstram as seguintes considerações. Pensemos em um quebra-cabeça. Trata-se de reunir numerosas pequenas peças de formato irregular, que ligadas umas às outras reconstituem o quadro completo. Pressupõe-se que todas as peças que compõem o quadro inteiro estão disponíveis e que só tais peças estão à disposição e são levadas em conta. Daí se segue que a pessoa que procura resolver o quebra-cabeça deve conhecer a priori que cada peça deve ter de fato um lugar determinado, que apenas as peças disponíveis têm um lugar determinado e, finalmente, que todas as peças juntas completarão o quadro. A tarefa da pessoa é então encontrar o lugar certo de cada peça.

A té certo ponto "o processo lógico e fenomenológico" no sentido hegeliano é semel hante a este quebra-cabeça. O teorista deve saber de antemão o que o quadro inteiro (o conjunto da lógica e da fenomenologia) é ou deve ser; ele tem à sua disposição um imenso material (conceitos e Gestalten da consciência) em relação ao qual ele sabe que deve encontrar o lugar "certo" de cada conceito/ Gestalt dentro do conjunto do processo. Não há nenhuma "derivação direta" de um novo conceito ou Gestalt do precedente. Há ape-

51 Cf. especialmente os ensaios do autor mencionados na nota 38. 
nas a tarefa de encontrar holisticamente o lugar certo de cada peça, i.e. de cada conceito ou Gestalt.

Fica agora claro onde reside o problema fundamental: Qual é o lugar ou o papel do "teorista", de "nós (os expositores)"? Como Hegel explica e justifica este lugar e este papel? Nenhuma explicação e justificação neste sentido pode ser encontrada em Hegel.

\subsection{Há lugar para a idéia fenomenológica no interior de uma filosofia sistemática rigorosa?}

Como se mostrou na Parte 1 deste artigo, no sistema da maturidade de Hegel a Fenomenologia aparece em três lugares muito diferentes: em primeiro lugar, como o conjunto da obra enquanto introdução e justificação do ponto de vista da ciência (lógica); em segundo lugar, em relação às suas "estruturas elementares", como uma sub-seção da Filosofia do Espírito na Enciclopédia; em terceiro lugar, como um todo, enquanto articulação do segundo silogismo no fim da Enciclopédia: como a exposição fenomenológica do conjunto do sistema da filosofia. Como avaliar sistematicamente ${ }_{1+2}$ este status da Fenomenologia? Três aspectos serão brevemente considerados.

[1] A resposta a esta questão depende da maneira como se concebe a filosofia. O autor desenvolveu uma concepção sistemática de filosofia baseada no conceito de estrutura teorética. Filosofia é em primeiro lugar e acima de tudo uma teoria universal. As teorias filosóficas consistem de sentenças teoréticas eas sentenças teoréticas, como se mostrou acima, são estruturadas de tal modo que nelas não há qualquer referência explícita ou implícita a al go como um sujeito, falante, etc. Trata-se de sentenças indicativas precedidas - explícita ou com maior freqüência implicitamente - pelo operador teorético “É o caso que... (por exemplo: ö)".

Na perspectiva desta filosofia (que o autor denomina "a filosofia estruturalsistemática") uma avaliação sistemática ${ }_{1+2}$ da Fenomenologia deve tratar principal mente e, em certo sentido, quase exclusivamente da questão, que lugar deveria atribuir a filosofia à dimensão sujeito/ subjetividade? A filosofia estrutural-sistemática tem claramente uma resposta geral para tal questão: a esta dimensão só pode ser atribuído um lugar claramente secundário. Segue-se daí que a Fenomenologia não pode ser considerada uma obra altamente interessante para a filosofia estrutural-sistemática.

De acordo com a filosofia estrutural-sistemática, a dimensão do sujeito (subjetividade) deve ser submetida a uma radical depotenciação: à subjetividade já não pode ser atribuída a posição privilegiada que lhe é conferida na modernidade. A razão mais fundamental para esta afirmação é muito simples. A filosofia é essencialmente uma teoria (uma teoria universal). 
Numa perspectiva mentalística não é possível fazer jus a este aspecto fundamental da filosofia. Com efeito, quando a linguagem (com todo o campo quea envolve, especial mente a lógica, no sentido moderno, a semântica, etc.) entra na cena filosófica é - entre outras coisas - possível, pela primeira vez, estabelecer um critério para a teoreticidade, um critério que pode ser denominado o critério lingüístico da teoreticidade. Este critério foi brevemente descrito e explicado acima. Trata-se da estrutura lingüística das sentenças indicativas, i.e. teoréticas. Estas sentenças têm a estrutura: “É o caso que (p.ex.: ö)".

Notou-se acima que esta estrutura não inclui qualquer referência a algo como sujeitos, falantes, ou algo semelhante. As sentenças teoréticas articulam ou expressam seus conteúdos literalmente, de modo absoluto. Mas toda filosofia da subjetividade infringe esta lei estrutural fundamental, porque toda sentença que ocorre no quadro referencial de uma filosofia da subjetividade tem a estrutura: "Na perspectiva da subjetividade (dialéticoespeculativa, transcendental, empírica, etc.) é o caso que..." Evidentemente, nenhuma sentença dessa espécie tem o status absoluto que as sentenças teoréticas requerem. Além do mais, os filósofos da subjetividade incorrem permanentemente em uma profunda incoerência: com efeito, eles sempre formulam as sentenças teoréticas, pelo menos, implicitamente, atribuindoIhes um status absoluto irrestrito. Mas isso contradiz a posição que eles mantêm explicitamente. Esta posição implica necessariamente que as sentenças estabelecidas nesta perspectiva possuem apenas um status extremamente restrito, a saber: "Na perspectiva da subjetividade (dialéticoespeculativa, transcendental, ou outra...) é o caso que...".

O reconhecimento desta característica central de qualquer filosofia que se entende como tendo um status teorético exige o que pode ser chamado de depotenciação de toda a dimensão da subjetividade e de todos os seus ramos. Certamente, isso não implica que a dimensão da subjetividade deva desaparecer. A subjetividade é uma dimensão real e precisa, portanto, ser tomada em consideração - mas tão somente na posição que ela merece ocupar no interior da dimensão teorética. Esta posição é secundária.

Pode parecer de certo modo estranho considerar Hegel como um adepto da filosofia da subjetividade. Pode-se apontar para o fato que ele sempre se esforçou por superar a dualidade de sujeito e objeto, que, segundo ele, "a ciência pura [...] contém o pensamento, na medida em que ele é igualmente a Coisa em si mesma, ou [contém] a Coisa em si mesma na medida em que ela é igualmente o pensamento puro", etc. ${ }^{52}$ Com efeito, é inegável que se podem encontrar em seus escritos formulações interessantes que à primeira

\footnotetext{
52 die Wissenschaft [...] den Gedanken [enthält], insofern er ebensosehr die Sache an sich selbst ist, oder die Sache an sich selbst, insofern sie ebensosehr der reine Gedanke ist. (WL I 30)
} 
vista parecem articular uma posição muito distante da dimensão da subjetividade. Mas a resposta a esta objeção resulta diretamente do que foi mostrado neste artigo: o pensar/ saber absoluto, o "conceito", segundo Hegel, é na realidade a subjetividade absolutizada. Trata-se da subjetividade, enquanto se articula como a realidade absoluta. Muitos intérpretes de Hegel não percebem quão radical, quão sutil e quão altamente sofisticado éo ramo hegeliano da filosofia da subjetividade. Baste apontar para um exemplo. A pós a última passagem citada acima, na qual ele estabelece a identidade de "Gedanke" e "Sache", Hegel escreve:

Como ciência, a verdade é a pura consciência de si mesmo, enquanto se desenvolve, e tem a figura do Si-mesmo, de modo que o que é em si e para si é o conceito, enquanto saber, e o conceito, como tal, é, por sua vez, o que é em si e para si. (Ciência da Lóg. I 30-31) 53 $^{3}$

[2] O que foi dito em [1] não representa a última palavra quanto à resposta à questão acerca do lugar da idéia fenomenológica na filosofia sistemáti$\mathrm{Ca}_{1+2}$. Certamente, o status mentalístico da Fenomenologia tem de ser rejejtado, se se aceita o caráter absoluto das sentenças teoréticas. Mas há al guns aspectos na idéia fenomenológica que são dignos de atenção, porque eles podem ser considerados - positiva ou negativamente - como inspiradores. Um de tais aspectos é a idéia de uma introdução ou justificação do "ponto de vista filosófico". Como ébem sabido, a Fenomenologia, sob este aspecto, levantou sempre questões al tamente intrigantes tanto para a interpretação da filosofia de Hegel como para a compreensão da filosofia em geral. Como entender o seu caráter de ser uma introdução ou justificação? Ambos os conceitos são extremamente problemáticos e, na verdade, necessitam uma explicação cuidadosa. A declaração fundamental de Hegel que a Fenomenologia, como "caminho para a ciência já é ela mesma ciência (dieser Weg zur Wissenchaft sel bst [ist] schon Wissenschaft)" (Fenom. I 72; PhG 68 [61]) articula uma intuição importante, se o "caminho para a ciência=filosofia" é interpretado como significando que o esclarecimento do que ciência=filosofia é, em última análise, tem como sua tarefa elaborar e estabelecer um quadro de referência teorético para a filosofia. Ora, esta elaboração e esta definição são já genuína filosofia, uma vez que não são nada mais do que uma auto-explicação e uma auto-apresentação da própria filosofia (que mais poderiam ser?...).

Quanto à justificação, este conceito é muito mais problemático, não obstante o incrível e amplo uso que dele fazem muitos filósofos hoje. Em que base poderia o ponto de vista filosófico ser "justificado"? "Justificação" é um conceito que pressupõe muitos outros conceitos e muitas admissões funda-

${ }^{53}$ Als Wissenschaft ist die Wahrheit das reine sich entwickelnde Selbstbewusstsein und hat die Gestalt des Selbsts, dass das an und für sich Seiende gewußter Begriff, der Begriff als solcher aber das an und für sich Seiende ist. (WL I 30-31) 
mentais. Como podem elas ser verificadas? "Justificação" só pode ser considerado um conceito dotado de significado sob a condição que designe um procedimento filosófico, i.e. um procedimento que já é parte integrante da própria filosofia. Em última análise, a parte significativa subjacente à intuição acerca de "justificação" só pode ser articulada com a elaboração do quadro referencial teorético da filosofia, cuja justificação está em questão. ${ }^{54}$

[3] Finalmente, há um aspecto ulterior da “idéia fenomenológica” que merece ser levado em consideração e que, depois de ter sido submetido a uma transformação significativa, pode ser integrado no interior de uma filosofia sistemática ${ }_{1+2}$. Trata-se da idéia hegeliana de uma pluralidade de formas ou Gestalten da consciência juntamente com suas determinações lógicas correspondentes. Cada uma destas formas ou Gestalten e cada determinação lógica correspondente constitui um determinado ponto de vista, como Hegel explicitamente reconhece. ${ }^{55}$ Esta idéia hegeliana pode - e deve - ser transformada na idéia de uma pluralidade de quadros de referência teoréticos, o que acontece quando o vocabulário mentalístico, as questões mentalísticas, e os procedimentos mentalísticos, que caracterizam a Fenomenologia, são abandonados.

Se a idéia de um ponto de vista teorético for elaborada exatamente e em detalhe, chegar-se-á ao conceito de quadro de referência teorético. E este conceito é imensamente importante para a fil osofia. É dificilmente concebível que a filosofia hoje possa contestar a afirmação que temos de reconhecer e aceitar a pluralidade dos quadros de referência teoréticos..$^{56} \mathrm{Em}$ total discordância com H egel, contudo, é preciso sublinhar que não tem sentido pretender chegar à "absolute Gestalt" no sentido do "ponto de vista absoluto", como Hegel claramente tentou. (Efetivamente, ele não só tentou alcançar o ponto de vista absoluto, mas também estava convencido de têlo realmente alcançado e desdobrado). De modo semelhante, não podemos pretender ter articulado, nem podemos mesmo esforçar-nos por articular "o quadro de referência teorético absoluto". A tarefa do filósofo que reflete sobre estas questões fundamentais étentar desenvolver um quadro de referência teorético que seja dotado de um maior grau de inteligibilidade do que qual quer outro quadro de referência teorético disponível. Certamente, esta posição suscita muitos problemas difíceis. Mas não é possível tratá-los neste artigo. ${ }^{57}$

${ }^{54}$ Cf. Estrutura e ser, p. 67-95.

55 Cf. p. ex. o que Hegel diz acerca da determinação lógica "substância": “ [...] die Philosophie, welche sich auf den Standpunkt der Substanz stellt und darauf stehen bleibt, [ist] das System des Spinoza (WL II 216).

56 Cf. para esta questão Estrutura e ser, especialmente p. 638ss.

57 Cf. ib. especialmente p. 321ss e Capítulo 6. 


\section{Conclusão}

A resposta tentativa à questão posta no início distingue dois tipos de influência e fascinação que a obra de Hegel exerceu e continua a exercer. A primeira consiste na tentativa de encontrar na Fenomenologia al guns tópicos e intuições al egadamente fascinantes. Isso aconteceu na década de 30 do século passado na França quando Alexandre Kojève apresentou sua interpretação da Fenomenologia (e do conjunto da filosofia hegeliana), baseando-se decisivamente na dialética senhor-escravo e no conceito de reconhecimento, que dela deriva. A lgo semel hante está acontecendo atual mente: há intérpretes, especial mente nos Estados Unidos - exemplos eminentes são os assim-chamados "Neo-hegelianos de Pittsburgh", Robert Brandom e John McDowell - que consideram ter descoberto temas pragmatistas em al gumas passagens da Fenomenologia. Brandom considera a tese idealista de Hegel, segundo a qual "a estrutura e a unidade do conceito é a mesma que a estrutura e a unidade do self como a maneira para Hegel de tornar efetiva" a tese semântica pragmatista segundo a qual, na versão de Brandon, "os conceitos não podem ter nenhum conteúdo senão o quelhes é conferido pelo uso".$^{58}$ Tanto a abordagem de Kojève quanto a semântico-pragmatista são, contudo, manifestamente unilaterais e, portanto, não fazem jus a Hegel e não podem fornecer interpretações coerentes desta famosa obra. Por essa razão, elas impedem decisivamente a avaliação fil osoficamente bem fundamentada da posição filosófica de Hegel.

A segunda espécie de influência e fascinação é inteiramente diferente. Ela emerge da tendência de muitos filósofos a considerar de uma só vez e de maneira global o imenso reino de experiências da mente humana, incluindo consciência, auto-consciência, razão e espírito. Eles facilmente encontram o que estão procurando na Fenomenologia. Com efeito, nesta obra Hegel proclama explicitamente que pretende articular o imenso reino da experiência da consciência ao desdobrar a história inteira da dialética de suas Gestalten. À primeira vista tal programa aparece para muitos filósofos como uma tarefa e uma visão filosóficas fascinantes. Mas o que esses filósofos em geral deixam de fazer é desenvolver uma análise rigorosa e detal hada do processo completo que Hegel afirma ter descrito.

Endereço do Autor:

Philosophie-Department, Universität München

Geschwister-Scholl-Platz I

80539 München, Germany

puntel@rz.uni-muenchen.de

58 R. Brandom, Tales from the Mighty Dead, p. 210 (cf. nota 6). 